Article

\title{
Effects on the Properties after Addition of Lithium Salt in Poly(ethylene oxide)/Poly(methyl acrylate) Blends
}

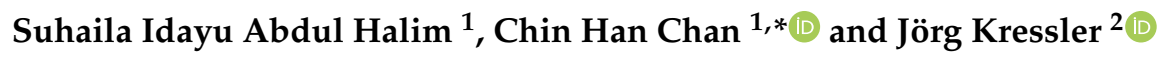 \\ 1 Faculty of Applied Sciences, Universiti Teknologi MARA, Shah Alam 40450, Selangor, Malaysia; \\ suhailaidayu@gmail.com \\ 2 Faculty of Natural Sciences II, Institute of Chemistry, Martin-Luther University Halle-Wittenberg, \\ 06120 Halle, Germany; joerg.kressler@chemie.uni-halle.de \\ * Correspondence: cchan_25@yahoo.com.sg
}

Received: 7 October 2020; Accepted: 7 December 2020; Published: 11 December 2020

\begin{abstract}
The studies of phase behavior, dielectric relaxation, and other properties of poly(ethylene oxide) (PEO)/poly (methyl acrylate) (PMA) blends with the addition of lithium perchlorate $\left(\mathrm{LiClO}_{4}\right)$ were done for different blend compositions. Samples were prepared by a solution casting technique. The binary PEO/PMA blends exhibit a single and compositional-dependent glass transition temperature $\left(T_{\mathrm{g}}\right)$, which is also true for ternary mixtures of $\mathrm{PEO} / \mathrm{PMA} / \mathrm{LiClO}_{4}$ when $\mathrm{PEO}$ was in excess with low content of salt. These may indicate miscibility of the constituents for the molten systems and amorphous domains of the systems at room temperature from the macroscopic point of view. Subsequently, the morphology of PEO/PMA blends with or without salt are correlated to the phase behavior of the systems. Phase morphology and molecular interaction of polymer chains by salt ions of the systems may rule the dielectric or electric relaxation at room temperature, which was estimated using electrochemical impedance spectroscopy (EIS). The frequency-dependent impedance spectra are of interest for the elucidation of polarization and relaxation of the charged entities for the systems. Relaxation can be noted only when a sufficient amount of salt is added into the systems.
\end{abstract}

Keywords: poly(ethylene oxide); poly(methyl acrylate); phase morphology; dielectric relaxation

\section{Introduction}

Lithium (Li)-ion batteries that exhibit appreciably high energy and power density are the choice of the electrochemical energy storage for portable electronics/devices, hybrid/full electric vehicles, etc. [1-3]. Li-ion batteries are rechargeable devices, where both electrodes are intercalation materials, and the commercial electrolyte is commonly Li salt dissolved in a mixture of organic solvents [3-5]. Extensive studies on organic solvent-free electrolytes, for example on solid polymer electrolytes (SPEs), have been carried out [6,7] since 1980. One of the popular polymer hosts for SPEs is poly(ethylene oxide) (PEO), which is a semi-crystalline polymer with crystallinity amount up to $70 \%$ [8-12]. It is widely accepted that ionic percolation mainly takes place in the amorphous regions of polymer $[6,11]$.

One of the strategies to enhance the ionic conductivity $\left(\sigma_{\mathrm{DC}}\right)$ of binary mixtures of PEO and Li salt is to add a second polymer that is miscible or homogenous with PEO (in the melt or amorphous phase), for example poly(methyl acrylate) [9,13], poly(methyl methacrylate) [14], polyacrylate (PAc) [15], poly(propylene oxide) (PPO) [16], poly ( $\varepsilon$-caprolactone) (PCL) [17,18], etc., with the aim to suppress the crystallinity of PEO. However, suppression of crystallinity in PEO alone does not always lead to enhancement of conductivity for the systems as compared to the PEO-salt systems [19]. This is due to highly complex systems that develop when Li salt is added to the miscible or homogenous PEO 
(binary) blends at room temperature, let say at $25^{\circ} \mathrm{C}$, where the conductivity is measured for useful applications. Therefore, the salt content, blend compositions, the glass transition temperature $\left(T_{\mathrm{g}}\right)$ of the second polymer, and homogenous or heterogeneous amorphous phase of the ternary systems will affect the conductivity of the materials.

In this study, high molar mass PEO is blended with an amorphous polymer, i.e., PMA, with the $T_{\text {g }}$ roughly at $10^{\circ} \mathrm{C}$, and with addition of lithium perchlorate $\left(\mathrm{LiClO}_{4}\right)$. PEO/PMA blends are known to be homogenous above melting point of PEO $\left(\sim 65^{\circ} \mathrm{C}\right)$ and in the amorphous phase for all blend compositions under the experimental condition $[13,20]$. Upon cooling from the melt, the PEO starts to crystallize and phase separates from the mixture. Hence, there is co-existence of PEO crystalline phase and the amorphous mixture (amorphous PEO and PMA) at $25^{\circ} \mathrm{C}$ (room temperature).

The addition of the ternary component, the Li salt to PEO/PMA blends may trigger phase separation of PEO and PMA in the amorphous phase of the system depending on the composition of the blends and the salt content [13]. Hence, the amorphous phase of the ternary systems can be homogenous or heterogeneous (c.f. text below) depending on the composition of the blends as well as the salt content, which in the end may lead to enhancement or reduction on conductivity as compared to the binary PEO-salt system at a constant mass fraction of salt $\left(W_{\mathrm{S}}\right)$ or at constant mass fraction of $\mathrm{PEO}\left(W_{\mathrm{PEO}}\right)$. It is noteworthy that these polymer electrolyte systems are becoming more complex and complicated in the ternary mixture at $25^{\circ} \mathrm{C}$.

As a result, these composition-dependent ternary systems of $\mathrm{PEO} / \mathrm{PMA} / \mathrm{LiClO}_{4}$ will have different morphologies, which lead to different conductivities at constant salt content or constant blend composition. The composition-dependent morphologies of the ternary mixtures in the amorphous region are listed in Table 1 as an overview.

Table 1. Brief interpretations on the morphology of the ternary mixtures in the amorphous phase.

\begin{tabular}{|c|c|c|}
\hline Situation & Possible Morphology & System \\
\hline (I) & $\begin{array}{l}\text { Amorphous polyethylene oxide (PEO) } \\
\text { incorporated with Li-salt/amorphous } \\
\text { polymethyl acrylate (PMA) }\end{array}$ & $\begin{array}{l}\text { PEO/PMA blends with salt content more } \\
\text { than } ~ 5 \text { wt. } \% \text { when PMA is in excess }\end{array}$ \\
\hline (II) & $\begin{array}{l}\text { Amorphous mixture of PEO and PMA } \\
\text { incorporated with Li-salt }\end{array}$ & $\begin{array}{l}\text { PEO/PMA blends with salt content less } \\
\text { than } \sim 10 \text { wt. } \% \text { when PEO is in excess }\end{array}$ \\
\hline (III) & $\begin{array}{l}\text { Amorphous PEO incorporated with } \\
\text { Li-salt/pure Li-salt }\end{array}$ & $\begin{array}{l}\text { PEO with salt content more than } \sim 10 \\
\text { wt. } \%\end{array}$ \\
\hline (IV) & $\begin{array}{l}\text { Amorphous PEO incorporated with } \\
\text { Li-salt/amorphous PMA/pure Li-salt }\end{array}$ & $\begin{array}{l}\text { All PEO/PMA blends with salt content } \\
\text { more than 10 wt. } \%\end{array}$ \\
\hline
\end{tabular}

Situation (I) is based on the existence of two distinct phases (liquid-liquid separation) in the system and situation (II) assume two amorphous phases of PEO and PMA incorporated with Li-salt exist as a single phase. However, another possibility may emerge in the binary and ternary systems with much higher concentration of salt, where the precipitation of Li-salt may be observed out of the polymer matrix when the mixtures are up to saturation, i.e., situations (III) and (IV) [21]. Situation (IV) considers the two amorphous phases of PEO and PMA are no longer homogeneous (miscible) as in (II), along with the presence of pure salt (salt precipitation) after the addition of sufficiently high salt content or at blend composition with minor PEO. Morphology with situation (I) might be effective for conductivity enhancement, as it may increase the distribution of Li-salt into the preferred polymer phase, consequently increasing the polymer-salt interaction. In short, all the morphologies discussed above may play a vital part to the electrical phenomenology of PEO/PMA SPEs. Thus, we note here that frequency-dependent impedance studies are deemed important to elucidate the dielectric and electric relaxation of dipolar entities in the polymer electrolytes as impedance $(Z)$ is one of the central quantities in impedance spectroscopy.

This work is an extension of the previous contribution to the solid polymer electrolytes (SPEs). The scope of the discussion of these ternary $\mathrm{PEO} / \mathrm{PMA} / \mathrm{LiClO}_{4}$ systems were expanded with in-depth 
theoretical analyses and additional experiments as compared to the previous study [13]. Differential scanning calorimetry (DSC) was employed to estimate the properties of the amorphous phase (on the $T_{\mathrm{g}}$ ) as well as the crystalline phase (on the melting behavior and its crystallinity) of the ternary systems. Morphology and dielectric response of the systems were investigated by optical microscopy (OM) and electrochemical impedance spectroscopy (EIS), respectively. Besides, polarization and relaxation of dipoles in composition-dependent PEO/PMA blends after addition of Li-salt was studied by EIS and will be discussed.

\section{Experimental}

\subsection{Materials}

Characteristics of the polymers and salt are given in Table 2. The polymers were purified prior to further preparation. PEO was purified by dissolution in chloroform (Merck, Darmstadt, Germany) following with precipitation in $n$-hexane (Merck, Darmstadt, Germany). The as-received PMA in toluene was precipitated in $n$-hexane before blending. The $\mathrm{LiClO}_{4}$ was dried at $120^{\circ} \mathrm{C}$ for at least $24 \mathrm{~h}$.

Table 2. Characteristics of materials.

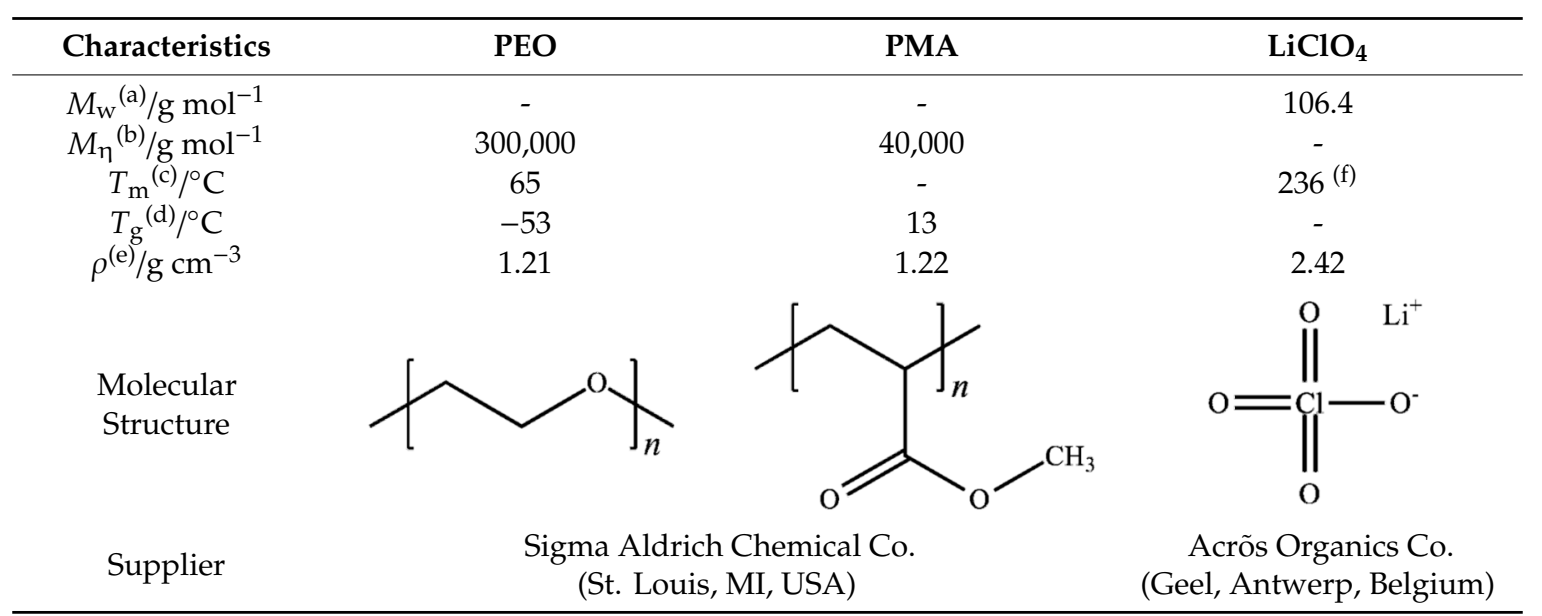

(a) Mass-average molar mass as determined by the supplier. ${ }^{\text {(b) }}$ Viscosity-average molar mass as determined by the supplier. ${ }^{(c)}$ Melting temperature of PEO estimated in this study. ${ }^{(d)}$ Glass transition temperature estimated in this study. (e) Density as determined by the supplier. ${ }^{(\mathrm{f})}$ Melting temperature from reference [22].

\subsection{Preparation of Samples}

Binary blends of PEO/PMA were prepared by using a solution casting technique. Solid film $\mathrm{PEO}_{80}$ denotes PEO/PMA 80/20 blend $(\mathrm{m} / \mathrm{m})$ and analogue sample coding for other compositions. Quantity $m_{i}$ represents mass of component $i$. The solid solution comprising of PEO, PMA, and $\mathrm{LiClO}_{4}$ were also prepared by solution casting technique. The mass fraction of polymer (PEO) and mass fraction of salt were estimated as below:

$$
W_{\mathrm{PEO}}=\frac{m_{\mathrm{PEO}}}{m_{\mathrm{PEO}}+m_{\mathrm{PMA}}+m_{\mathrm{S}}} \text { and } W_{\mathrm{S}} \frac{m_{\mathrm{S}}}{m_{\mathrm{PEO}}+m_{\mathrm{PMA}}+m_{\mathrm{S}}}
$$

Corresponding $W_{\mathrm{S}}$ to mole fraction of salt $\left(X_{\mathrm{S}}\right)$ and salt content $\left(Y_{\mathrm{S}}\right)$ is shown in Table A1 in Appendix A. All the components were dissolved in acetonitrile (ACN) and stirred for $24 \mathrm{~h}$ at $50{ }^{\circ} \mathrm{C}$. The solution was casted onto Teflon ${ }^{\circledR}$ dish and left to dry at room temperature until the solvent evaporated. The samples were oven dried at $50^{\circ} \mathrm{C}$ for no less than $24 \mathrm{~h}$ for removal of residual solvent. This was followed by heating the samples at $80^{\circ} \mathrm{C}$ for $\frac{1}{2} \mathrm{~h}$ under nitrogen atmosphere. Subsequently, the samples were isothermally crystallized at $25^{\circ} \mathrm{C}$ for $24 \mathrm{~h}$ in the convection oven before vacuum drying at $25^{\circ} \mathrm{C}$ for $24 \mathrm{~h}$. All samples were then kept in desiccators at $25^{\circ} \mathrm{C}$. Then, the samples were again vacuum dried at $25^{\circ} \mathrm{C}$ for $24 \mathrm{~h}$ prior to any characterization. 
The solution-cast samples were thermally treated under inert atmosphere above the melting temperature $\left(T_{\mathrm{m}}\right)$ of PEO for a certain period of time to erase the thermal history of the sample during the sample preparation pathway as well as for complete mixing of all components in the melt. The consistency in sample preparation is crucial for the reproducible properties reported here. Hence, the electrolyte systems discussed herein are close towards equilibrium condition.

\section{Characterization}

\subsection{Differential Scanning Calorimetry (DSC)}

The quantities $T_{\mathrm{g}}, T_{\mathrm{m}}$, and melting enthalpy $\left(\Delta H_{\mathrm{m}}\right)$ of samples were analyzed from the heating cycle of DSC. The samples were studied using DSC TA Q200 (TA Instrument, New Castle, DE, USA) equipped with RCS90 cooling system (TA Instrument, New Castle, DE, USA). Nitrogen gas was purged during analysis at a rate of $50 \mathrm{~mL} \mathrm{~min}^{-1}$ to avoid thermo-oxidative degradation of samples. Roughly 10 to $15 \mathrm{mg}$ of thin film samples were encapsulated in aluminum DSC sample pans for analysis. Calibration of DSC using high-purity indium standard was done prior to analysis. Samples were heated up from $-90{ }^{\circ} \mathrm{C}$ to $80^{\circ} \mathrm{C}$ at a heating rate of $10{ }^{\circ} \mathrm{C} \mathrm{min}-1$. The $T_{\mathrm{g}}$ was estimated at half extrapolated change in heat capacity $\left(\Delta C_{\mathrm{p}}\right)$ or adopted from Moynihan's approach (if relaxation endotherm overlaid the glass transition) for estimation of $T_{\mathrm{g}}$ in a more precise manner [21]. $T_{\mathrm{m}}$ was extracted as the maximum of the endothermal peak in the DSC trace. $\Delta H_{\mathrm{m}}$ was estimated from the area underneath the melting endotherm. The crystallinity $\left(X^{*}\right)$ of the PEO phase in the blends was estimated by Equation (2).

$$
X^{*}=\left(\frac{\Delta H_{\mathrm{m}}}{\Delta H_{\mathrm{ref}} \cdot W_{\mathrm{PEO}}}\right) \times 100 \%
$$

where $\Delta H_{\text {ref }}=188.3 \mathrm{~J} \mathrm{~g}^{-1}$ is the melting enthalpy of $100 \%$ crystalline PEO, and $W_{\text {PEO }}$ is the mass fraction of PEO in the blends.

\subsection{Optical Microscopy (OM)}

The morphology of each sample was captured using AxioVision Control software (Zeiss, Oberkochen, Germany) connected to the Axioplan 2 imaging polarizing optical microscope (Zeiss, Oberkochen, Germany) equipped with a Linkam TM600/s hotstage (Linkam, Surrey, UK). Three percent $(\mathrm{m} / \mathrm{v})$ of the sample was dissolved in acetonitrile and was heated at $50^{\circ} \mathrm{C}$ for $24 \mathrm{~h}$. After dissolution, the polymer solution was casted drop-by-drop on top of a glass cover slip and allowed to dry at room temperature for at least $24 \mathrm{~h}$. The sample was heated up at $80^{\circ} \mathrm{C}$ and was annealed for $\frac{1}{2} \mathrm{~h}$, followed by quenched cooling and isothermal treatment at $T_{\mathrm{C}}=25^{\circ} \mathrm{C}$ until complete crystallization. Minimum 5 micrographs were captured with $10 \times$ magnification at two different temperatures $T=80^{\circ} \mathrm{C}$ (with non-polarized mode) with annealing time of $\frac{1}{2} \mathrm{~h}$ to give sufficient time for complete mixing in the melt and at $T=25^{\circ} \mathrm{C}$ (with polarized mode) with annealing time of $24 \mathrm{~h}$ for complete crystallization of PEO.

\subsection{Impedance Spectroscopy (IS)}

Impedance measurement of each sample was done at $25{ }^{\circ} \mathrm{C}$ using a Hioki $3532-50 \mathrm{Hi}$ Tester impedance analyzer (Hioki, Chubu, Japan) equipped with a computer for data collection over the frequency range from $50 \mathrm{~Hz}$ to $2 \mathrm{MHz}$. Two stainless steel electrodes with a diameter of $20 \mathrm{~mm}$ were used as the current collector and the blocking electrode for the ions. The sample was placed in between the two blocking electrodes for measurement. The $\sigma_{\mathrm{DC}}$ value was estimated from the bulk resistance $\left(R_{\mathrm{b}}\right)$ following equation of $\sigma_{\mathrm{DC}}=L /\left(A \cdot R_{\mathrm{b}}\right)$, where quantities $L$ and $A$ denote thickness of the sample and surface area in touch with the two stainless steel disc electrodes, respectively. The quantity $L$ was measured with Digimatic Caliper (Mitutoyo, Kanagawa, Japan) at three different spots that were in contact to the electrodes. The quantity $L$ was averaged from the three measurements and the thickness of the dried samples is maintained within the range of $0.25-0.35 \mathrm{~mm}$. 
$\sigma_{\mathrm{DC}}$ was either estimated from both Nyquist plot and from the real $\left(Z^{\prime}\right)$ or imaginary parts $\left(Z^{\prime \prime}\right)$ values of impedance at frequency for fully stabilized network $\left(f_{\max }^{Z^{\prime \prime}}\right)\left[Z^{\prime}\left(f_{\max }^{Z^{\prime \prime}}\right)\right.$ and $\left.Z^{\prime \prime}\left(f_{\max }^{Z^{\prime \prime}}\right)\right]$ at maximum of $Z^{\prime \prime}$, and each result obtained by both methods is maintained with an error of less than or equal to $5 \%$. Values of $\sigma_{\mathrm{DC}}$ reported here were the averages of three impedance analyses from three different spots of the thin sample with errors of $\sigma_{\mathrm{DC}}$ approximately at $10 \%$.

\section{Results and Discussion}

\subsection{Glass Transition Temperature}

Glass transition temperature $\left(T_{\mathrm{g}}\right)$ may be seen as one criterion of the miscibility of a polymer blend from a macroscopic point of view. The blend is seen as a single-phase polymer blend (miscible blend) when it exhibits a single and composition-dependent $T_{\mathrm{g}}$. Immiscibility can be concluded when two $T_{\mathrm{g}} \mathrm{s}$ that are approximately close to the $T_{\mathrm{g}}$ of parent polymers are observed. The Fox equation as in Equation (3) is commonly referred to for the evaluation or prediction of the $T_{\mathrm{g}}$ values of miscible binary blends.

$$
\frac{1}{T_{\mathrm{g}}}=\frac{W_{\mathrm{A}}}{T_{\mathrm{g}, \mathrm{A}}}+\frac{W_{\mathrm{B}}}{T_{\mathrm{g}, \mathrm{B}}}
$$

where $W_{\mathrm{A}}, T_{\mathrm{g}, \mathrm{A}}$ and $W_{\mathrm{B}}, T_{\mathrm{g}, \mathrm{B}}$ represent the mass fraction and $T_{\mathrm{g}}$ of the respective polymer. The dashed curve in Figure $1 \mathrm{~b}$ is calculated after Equation (3). The entire composition of semi-crystalline/amorphous PEO/PMA blends in this study exhibit only a single and composition-dependent $T_{\mathrm{g}}$. The heating cycle of DSC thermograms are displayed in Figure 1a. Moreover, the experimental $T_{\mathrm{g}}$ values are in good agreement with the $T_{\mathrm{g}} \mathrm{s}$ predicted after the Fox equation. This may suggest that the polymer pair is miscible and homogeneous in the amorphous phase as well as in the molten state under this experimental condition for all compositions.
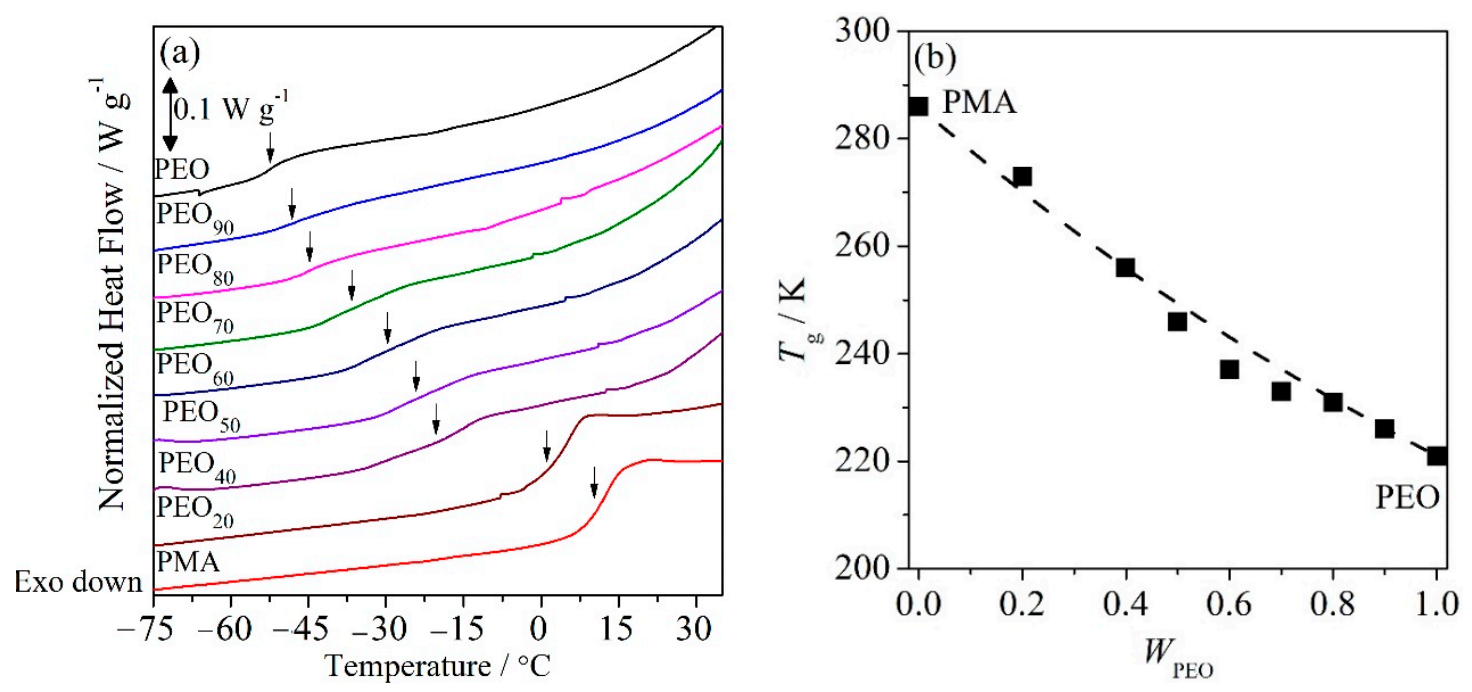

Figure 1. (a) Differential scanning calorimetry (DSC) thermograms of poly(ethylene oxide) (PEO)/poly (methyl acrylate) (PMA) blends and (b) variation of $T_{\mathrm{g}}$ of PEO/PMA blends versus mass fraction of PEO; the dashed line represents the $T_{\mathrm{g}}$ estimated after Fox equation [Equation (3)].

Figure 2a displays that the $T_{\mathrm{g}}$ of PMA decreases with elevating salt content $\left(W_{\mathrm{S}}\right)$. Unlike PMA, $T_{\mathrm{g}}$ of neat PEO elevates with increasing $W_{\mathrm{S}}$. This phenomenon implies that the salt may be more soluble in PEO than PMA. It is interesting to note that the miscible PEO/PMA blends act differently with the addition of salt as shown in Figure 2. The blends with $W_{\mathrm{PEO}} \geq 0.7$ after the addition of salt $W_{\mathrm{S}}$ still show single-composition-dependent $T_{\mathrm{g}}$ for all studied salt concentrations $\left(W_{\mathrm{S}}=0-0.17\right)$, which may indicate miscibility of the ternary mixtures in the amorphous phase and in the molten state. $\mathrm{PEO}_{80}$ displays the highest $T_{\mathrm{g}}$ values at $W_{\mathrm{S}}=0-0.09$ as compared to other systems $W_{\mathrm{PEO}} \geq 0.7$ with 
the same amount of salt. It implies $\mathrm{PEO}_{80}$ may be an effective host for $\mathrm{LiClO}_{4}$ for the enhancement of the ionic conductivity. Normally, the increase in $T_{\mathrm{g}}$ indicates the stiffness of the polymer chains at an increasing temperature. In this case, the stiffness of the chain segments comes from the interaction of salt molecules and polymer chains. However, the increase in $T_{\mathrm{g}}$ is only limited in the range of low salt content, as it increases up to saturation of the mixture due to the solubility limit of salt in the respective polymers $[23,24]$. When $W_{\mathrm{PEO}} \leq 0.6$ at $W_{\mathrm{S}} \geq 0.05$, the heterogeneity in the melt is inferred (i.e., liquid-liquid phase separation). It is deduced by the presence of two $T_{\mathrm{g}} \mathrm{s}$ that correspond to the parent polymers. From Figure $2 b$, another observation on the salt localization in the PEO phase more than PMA can be seen. In the immiscible systems, the $T_{\mathrm{g}} \mathrm{s}$ of PEO are constantly observed at slightly higher values than the neat PEO, whereas the $T_{\mathrm{g}} \mathrm{s}$ of PMA lie closely to that of the neat PMA.
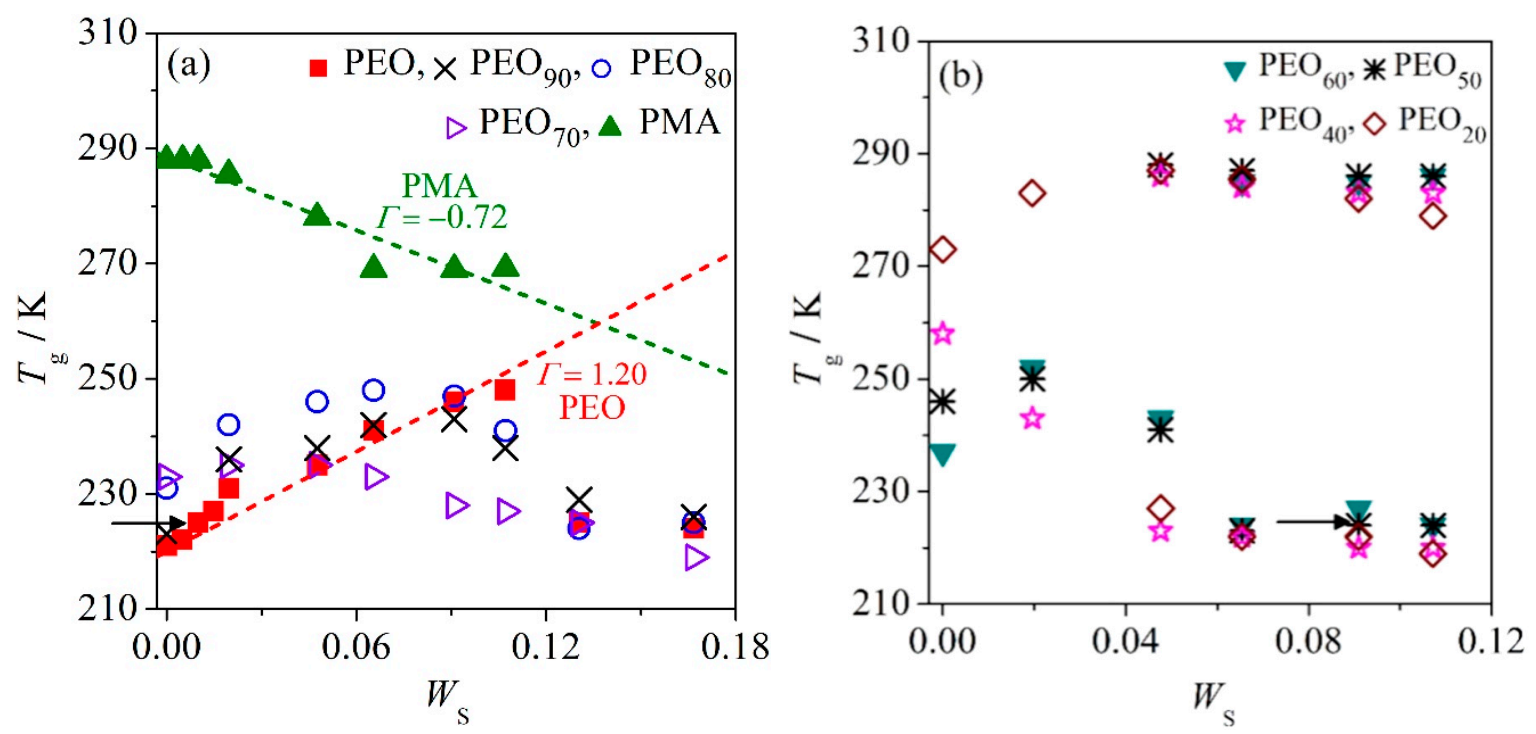

Figure 2. Variations of glass transition temperature $\left(T_{\mathrm{g}}\right)$ of (a) $W_{\mathrm{PEO}} \geq 0.7$ with linear regression of Equation (5) and (b) $W_{\mathrm{PEO}} \leq 0.6$ versus mass fraction of salt. Refer to the text for black arrows.

These $T_{\mathrm{g}}$ findings are in good agreement with the descriptions in the Introduction. Macroscopically, we observe situation (I) in the system with $W_{\mathrm{PEO}} \leq 0.6$ at $W_{\mathrm{S}} \geq 0.07$, and situation (II) in the system of $W_{\mathrm{PEO}} \geq 0.7$ at $W_{\mathrm{S}} \leq 0.10$. One may also observe the morphology of situation (III) in binary PEO-salt systems $\left(W_{\mathrm{PEO}}=1\right)$ at $W_{\mathrm{S}} \geq 0.10$ or beyond the salt saturation of the mixture. This is confirmed by the $T_{\mathrm{g}}$ of the respective mixture, which is closed to $T_{\mathrm{g}}$ of neat PEO. Furthermore, the precipitation of Li-salt was observed from optical inspection. The mixture with morphology (III) can be differentiated into salt-rich or salt-poor phases [21]. The salt-rich phase (phase") is mainly the pure salt phase, and salt-poor phase (phase') is the phase of highly diluted salt solution in the polymer phase. The salt content of salt-poor phase $\left(W_{\mathrm{S}}{ }^{\prime}\right)$ can be elucidated instantly from the plot of $T_{\mathrm{g}}$ against $W_{\mathrm{S}}$. Hence, the preferential localization of salt in the different polymer phases of the immiscible ternary mixture can be detected based on their respective $T_{\mathrm{g}}$ values. For instance, the $\mathrm{PEO}_{50}$ system added with $W_{\mathrm{S}}$ at 0.091 (black arrow in Figure 2b) is seen to contain approximately $1 \mathrm{wt} . \%$ of Li-salt dispersed in the PEO phase as the $T_{\mathrm{g}}$ of PEO in $\mathrm{PEO}_{50}$ is equivalent to $T_{\mathrm{g}}$ of $\mathrm{PEO}$ at $W_{\mathrm{S}}=0.01$ (black arrow in Figure 2a).

These ternary mixtures are miscible in the molten state and in the amorphous state under this experimental condition at sufficiently low salt content for all blend compositions. The mixtures are also miscible in molten state and in the amorphous phase at high salt content only when the PEO content is in excess, $W_{\mathrm{PEO}} \geq 0.7$. The liquid-liquid phase separation in the molten state may be deduced when the PEO content is $W_{\mathrm{PEO}} \leq 0.6$ at high salt content, $W_{\mathrm{S}} \geq 0.05$. The mixtures under discussion are comprised semi-crystalline/amorphous PEO/PMA SPEs. Hence, at $25^{\circ} \mathrm{C}$, the SPEs (which is true either for miscible or liquid-liquid phase-separated systems in the melt) are seen as liquid-solid phase separated systems due to the crystallization of PEO, which takes place upon cooling from the melt. 
The morphological studies of these SPEs that will be discussed in the subsequent section were carried out at temperatures $T=80^{\circ} \mathrm{C}$ and $T=25^{\circ} \mathrm{C}$ using optical microscopy (OM) with the aim of elucidating the phase behavior of the mixture in the melt and in the liquid-solid form from the microscopic level aside from distinguishing the correlation between $T_{\mathrm{g}}$ and morphology. However, the correlation between the electrical properties and miscibility will not be attempted because only liquid-solid phase-separated systems at $25^{\circ} \mathrm{C}$ were studied in all cases. Instead, preferential localization of salt in different polymer phases and the percolation path of the systems will be correlated to the relaxation and conductance of the systems.

From Figure 2a, we may also discuss the variation of $T_{\mathrm{g}}$ of the polymer blends that are still miscible in the molten and amorphous state after the addition of salt, for instance, $W_{\mathrm{PEO}} \geq 0.7$, in terms of thermodynamics based on the empirical observation [21]. The quantity of $T_{\mathrm{g}}$, and its $\Delta C_{\mathrm{P}}$ can be correlated as follows

$$
\ln \left(\frac{T_{\mathrm{g}}}{T_{\mathrm{g}}^{\mathrm{o}}}\right)=\frac{-\Delta S \text { glass }}{\Delta C_{\mathrm{P}}}
$$

$\Delta S^{\text {glass }}$ denotes the change in entropy of the glassy state after addition of salts that indirectly describes the deviation of the glass from the equilibrium. Equation (4a) illustrates the $\Delta C_{P}$ serves as the factor of proportionality of $-\Delta S$ glass and $T_{\mathrm{g}} / T_{\mathrm{g}}{ }^{\mathrm{o}}$. It is also true in the small range of $T_{\mathrm{g}}{ }^{\circ}$ to $T_{\mathrm{g}}$ that $\Delta C_{\mathrm{P}}$ is assumed to be independent of temperature (this observation is only applicable for thermodynamically miscible system, i.e., $\mathrm{PEO}-\mathrm{PEO}_{70}$ and PMA). Approximately, the quantity of $T_{\mathrm{g}} / T_{\mathrm{g}}{ }^{\mathrm{o}}$ may also be expressed as below

$$
\frac{T_{\mathrm{g}}}{T_{\mathrm{g}}^{\mathrm{o}}}=1+\frac{1}{T_{\mathrm{g}}^{\mathrm{o}}}\left(\frac{\partial T_{\mathrm{g}}}{\partial W_{\mathrm{S}}}\right) W_{\mathrm{S}}
$$

where the slope of plot $T_{\mathrm{g}}$ against $W_{\mathrm{S}}$ reads, $\frac{1}{T_{\mathrm{g}}^{\mathrm{g}}}\left(\frac{\partial T_{\mathrm{g}}}{\partial W_{\mathrm{S}}}\right) \equiv \Gamma$. The relationship of Equations (4) and (5) explains that the slope $\Gamma$ is interconnected to the partial molar entropy of the polymer pair in the ternary mixture that can be defined as $-\Delta \widetilde{S} \equiv \frac{\partial \Delta S^{\text {glass }}}{\partial W_{S}} \equiv \Gamma \overline{\Delta C_{P}}$. The mean value of $\Delta C_{P}$ of the polymer pair with different salt content is employed for estimation of $\Delta \widetilde{S}$ on condition that the ternary mixtures lies in the linearity. Furthermore, the glass transition is not accompanied by the change in energy; hence, we may formulate the related chemical potential or molar partial Gibbs free energy by

$$
\Delta G=-T_{\mathrm{g}}^{\mathrm{o}} \Delta \widetilde{S}
$$

The relationship of (4) and (5) shows when the slope $\Gamma$ is positive; the reduced $T_{\mathrm{g}} / T_{\mathrm{g}}{ }^{\mathrm{o}}$ of the mixture should be larger than unity and $\Delta S{ }^{g l a s s}$ would be negative. The positive gradient, $\Gamma>0$ reflects the freezing in of degrees of freedom of the polymer chains, whereas a negative gradient, $\Gamma<0$ shows the increase in the chain's degrees of freedom of the polymer. Experimentally, we observe that the salt affects the respective binary polymer-salt mixtures differently. PEO has a positive slope, $\Gamma>0$ with increasing $W_{\mathrm{S}}$, whereas PMA has a negative slope, $\Gamma<0$ with increasing $W_{\mathrm{S}}$. It suggests that the addition of salt in PEO leads to a higher stiffness of polymer chains whereas salt in PMA increases the flexibility of polymer chains. This discussion is also relevant for miscible ternary mixtures of $\mathrm{PEO} / \mathrm{PMA} / \mathrm{LiClO}_{4}$. The gradient $\Gamma$ of $W_{\mathrm{PEO}} \geq 0.7$ (i.e., $\mathrm{PEO}_{90}$ and $\mathrm{PEO}_{70}$ ) is reduced gradually with the increasing content of PMA. This indicates that addition of PMA in the PEO-salt systems increases the degree of freedom of the polymer chains in the miscible polymer blends (increasing the chain flexibility). Besides, it is worth noting that addition of certain amount of PMA into the PEO-salt system also drives the systems closer to equilibrium, as reflected in the $\Delta G$. The corresponding parameters $\Gamma$ of miscible PEO/PMA/LiClO 4 mixtures are summarized in Table 2.

\subsection{Crystallinity}

The degree of crystallinity $\left(X^{*}\right)$ of PEO in the ternary mixtures was estimated from Equation (2). The melting enthalpy $\left(\Delta H_{\mathrm{m}}\right)$ of PEO was obtained from the area under the melting endotherm 
of the thermograms. $\Delta H_{\mathrm{m}}$ is an essential quantity for the estimation of the degree of crystallinity $\left(X^{*}\right)$ for semi-crystalline polymer as the extent of the liquid-solid phase separation can be evaluated from crystallinity. The degree of crystallinity allows for rough estimation of the amorphous content. Hence, in principle, the reduction in crystallinity of the crystalline phase leads to an increase in the amorphous phase. It is widely accepted that ion percolation (conductivity) takes place only in the amorphous phase, thus, a rough estimation of the composition of the amorphous phase might be useful to understand electric conductivity. Equation (2) describes the degree of $X^{*}$ of PEO, which is directly proportional to $\Delta H_{\mathrm{m}}$ of $\mathrm{PEO}$, if the enthalpy of $100 \%$ crystallinity of PEO serves as the factor of proportionality

$$
X^{*} \propto \Delta H_{\mathrm{m}}
$$

Figure 3 depicts the $X^{*}$ of PEO in the ternary mixtures as a function of $W_{\text {PEO }}$. The dashed curve in the plot of $X^{*}$ against $W_{\mathrm{PEO}}$ is the constancy curve of crystallinity of PEO in the ternary mixtures. The suppression of $X^{*}$ from the constancy curve may be caused by the entrapment of the other component in the crystalline phase (in this case, $\mathrm{PEO}$ crystalline). Figure 3 illustrates that the $X^{*}$ of salt-free high molar mass PEO is $70 \%$ and starts to gradually level off to $\sim 20 \%$ with increasing of salt content up to $W_{\mathrm{S}}=0.167$ for binary PEO-salt system. The deviation from the PEO crystallinity constancy curve is observed for all systems with different blend compositions and salt content.

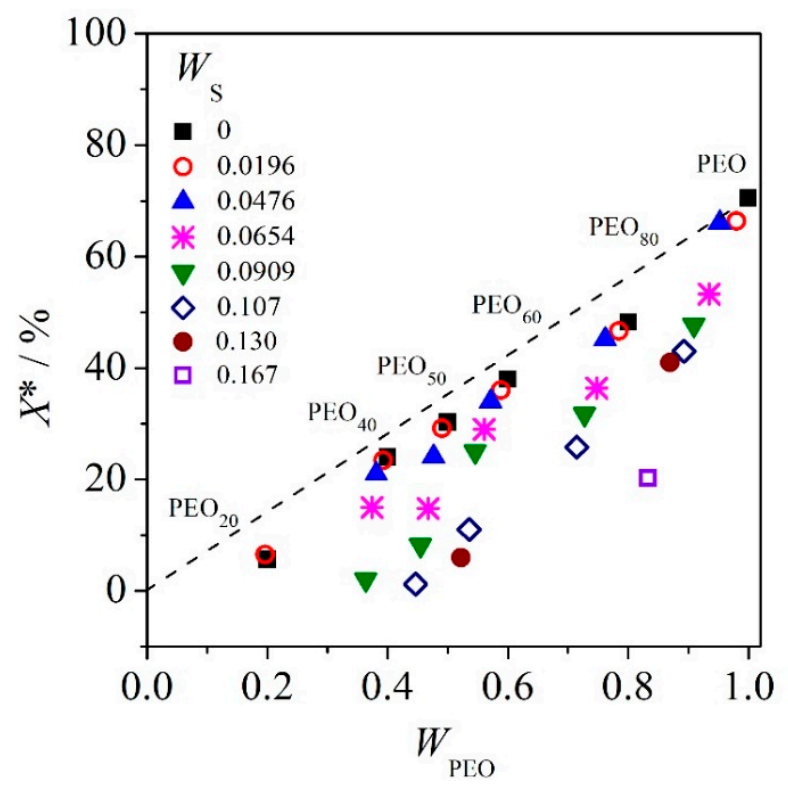

Figure 3. Crystallinity $\left(X^{*}\right)$ of $\mathrm{PEO}$ in the mixture of $\mathrm{PEO} / \mathrm{PMA} / \mathrm{LiClO}_{4}$ versus mass fraction of $\mathrm{PEO}$; the dashed curve indicates the loci of constancy of PEO crystallinity in PEO/PMA/LiClO 4 .

When PEO crystallinity in both salt-free and salt-added systems is at low salt content, $W_{\mathrm{S}} \leq 0.05$ displays no significant difference. The further suppression of $X^{*}$ of PEO is observed with higher content of salt, $W_{\mathrm{S}} \geq 0.07$, which is true for all blends under discussion. This indicates that with small amounts of salt in the mixture, the PEO crystallinity of the semi-crystalline/amorphous mixture is not really affected by the presence of salt and the further suppression of $X^{*}$ only starts with increasing amounts of salt in the mixture. These observations are true for both miscible and immiscible systems of this study. The suppression of crystallinity is normally true for miscible systems, as the crystallization behavior of the crystalline component in the immiscible systems (or liquid-liquid phase separated systems in the melt) is expected to have close approximation to the neat crystalline polymer, and it is normally unaffected by the presence of other components. Nevertheless, from this study, we note that salt and PMA are fond of PEO. Hence, we may see the exclusion of salt and PMA from PEO spherulites is not completely perfect, and the entrapment of amorphous phase of PEO, PMA, and salt in PEO spherulites 
lead to suppression of PEO crystallinity as well as depression of apparent melting temperature of PEO in the systems, which will be discussed in the next section.

\subsection{Melting Behavior}

The apparent melting temperature $\left(T_{\mathrm{m}}\right)$ was obtained from the maximum of the melting endotherm of the DSC curve. Figure 4 depicts the apparent $T_{\mathrm{m}}$ of PEO in the ternary mixtures as a function of the mole fraction of salt $\left(X_{S}\right)$. As mentioned before, the decrease in the crystallinity of the crystalline phase is generally influenced by the miscibility of the mixture, which is also true for the apparent $T_{\mathrm{m}}$. The depression of the apparent $T_{\mathrm{m}}$ of PEO is expected in miscible systems. We note here, both melting point and enthalpy are greatly depending on the amount of salt content. The apparent $T_{\mathrm{m}} \mathrm{s}$ of PEO of the as-prepared samples are depressed significantly from the constancy curve with increasing salt content for all compositions. This implies that the dissolution of Li-salt in the polymer matrix (in PEO) increases, which is in good approximation to the $T_{\mathrm{g}}$ as well as the crystallinity findings.

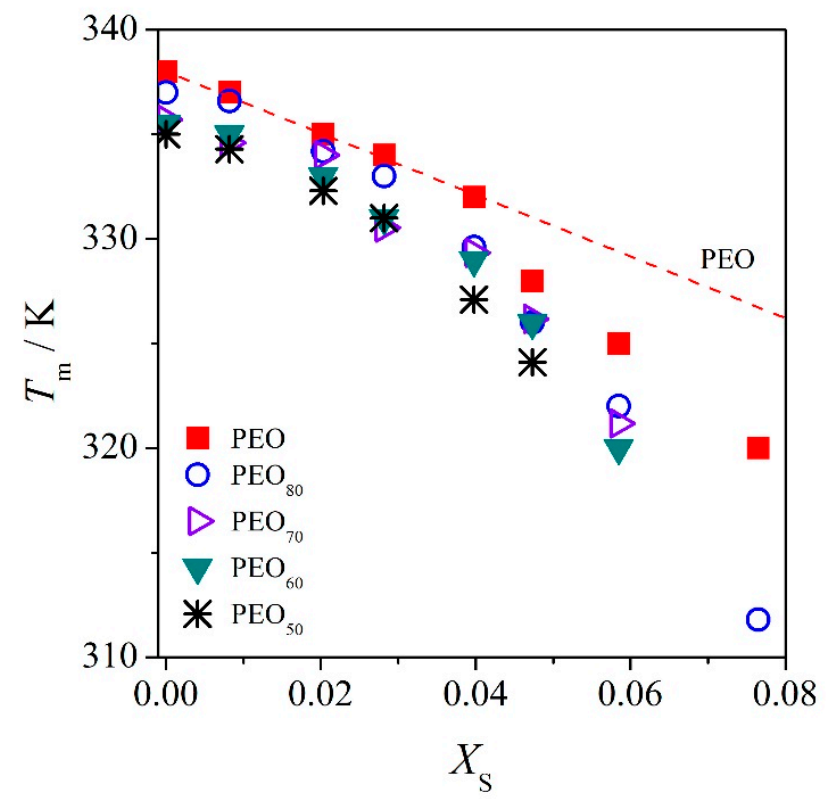

Figure 4. Apparent melting point $\left(T_{\mathrm{m}}\right)$ of $\mathrm{PEO}$ in the mixture of $\mathrm{PEO} / \mathrm{PMA} / \mathrm{LiClO}_{4}$ versus mole fraction of salt; the dashed curve is the linear regression for low salt content after Equation (8). $X_{S}$ represents the mole fraction of salt added to the system.

For binary polymer-salt mixtures with a crystalline constituent, we may employ the melting point depression of the crystalline polymer for estimation of deviations from perfect behavior $[25,26]$. In this case, when binary PEO/Li mixtures are completely miscible in the molten state, we employ the melting point depression of $\mathrm{PEO}$ for evaluation of the solid solution from perfect behavior (i.e., $\mathrm{PEO}-\mathrm{PEO}_{70}$ at $\left.W_{S} \leq 0.10\right)$. The estimation is expressed by

$$
T_{\mathrm{m}}=T_{\mathrm{m}}^{\mathrm{o}}+\frac{R\left(T_{\mathrm{m}}^{\mathrm{o}}\right)^{2}}{\Delta H_{\mathrm{ref}}}\left(\frac{\ln \gamma_{\mathrm{P}}}{\ln X_{\mathrm{P}}}+1\right) \ln X_{\mathrm{P}}
$$

where $X_{\mathrm{P}}$ denotes the mole fraction of PEO in the molten state, and $\gamma_{\mathrm{P}}$ is the corresponding activity coefficient for the solution, whereas the quantities $T_{\mathrm{m}}{ }^{\mathrm{o}}$ and $\Delta H_{\text {ref }}$ symbolize the melting temperature of neat PEO and the melting enthalpy of $100 \%$ crystallinity of PEO, respectively. For systems with low salt content (or the completely miscible systems, $\mathrm{PEO}-\mathrm{PEO}_{70}$ at $W_{\mathrm{S}} \leq 0.10$ ), we may assume $\mathrm{ln}$ $X_{P}=-X_{S}$. Hence, we see from Equation (8), the information about the activity coefficient $\gamma_{P}$ may be determined instantly from the linear plot of $T_{\mathrm{m}}$ against $X_{\mathrm{S}}$. This relationship is valid as long as the PEO crystalline phase crystallizes out from the molten mixture upon cooling from the melt. We apply 
Equation (8) to the as-prepared PEO/Li mixture for estimation of deviations from the ideal behavior (c.f. red-dashed curve in Figure 4). From Figure 4, we obtained $\Delta T / K=147.3 X_{S}$ for the PEO/Li mixture. The deviation of melting point depression from perfect behavior $\left[\Delta T\left(X_{S}\right)\right]$ for the $\mathrm{PEO} / \mathrm{Li}$ mixture, specifically at higher salt content $\left(X_{S}>0.05\right)$, is observed. This indicates at low salt contents that the melting point depression is not influenced by the salt, and it shows to a good approximation perfect behavior, displaying a very small $\gamma_{\mathrm{P}}=1+0.30 X_{S}$. This observation is also in good agreement with the findings discussed in references [26,27], where the estimation of the melting point depression of the high molar mass PEO $\left(M_{\eta}=3 \times 10^{5} \mathrm{~g} \mathrm{~mol}^{-1}\right)$ against $X_{\mathrm{S}}$ under similar experimental conditions yields $\gamma_{\mathrm{P}}$ close to unity $\left(1+0.38 X_{S}\right)$ as reported in reference [27]. This indicates that the PEO/Li system under these experimental conditions behaves nearly perfectly. Similar trend observations are found for other miscible mixtures, such as $\mathrm{PEO}_{90}, \mathrm{PEO}_{80}$, and $\mathrm{PEO}_{70}$, where drastic deviations only occur for systems with higher content of salt $\left(X_{S}>0.05\right)$. This implies that all systems that are still miscible with low salt contents under these experimental conditions behave nearly perfect as in binary PEO/Li systems. The results retrieved from Equation (8) are summarized in Table 3.

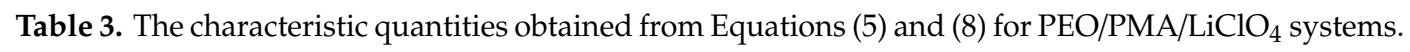

\begin{tabular}{|c|c|c|c|c|c|c|c|}
\hline Systems & $T_{\mathrm{g}} \mathrm{o} / \mathrm{K}$ & $\begin{array}{c}\Gamma \text { Retrieved from } \\
\text { Equation (5) }\end{array}$ & $\begin{array}{l}{\overline{\Delta C_{\mathrm{P}}}}^{(\mathrm{a})} / \\
\mathrm{J} \mathrm{mol}^{-1} \\
\mathrm{~K}^{-1}\end{array}$ & $\begin{array}{c}\Delta G / \\
\mathrm{kJ} \mathrm{mol}^{-1}\end{array}$ & $T_{\mathrm{m}} \mathrm{o} / \mathrm{K}$ & $\begin{array}{l}\text { Melting Point Depression } \\
\text { Retrieved from } \\
\text { Equation (8) [Correlation] }\end{array}$ & $\begin{array}{c}\text { Activity } \\
\text { Coefficient } \\
\left(\gamma_{\mathrm{p}}\right)\end{array}$ \\
\hline PEO & 220 & 1.20 & $8.9 \pm 2.6$ & 2.4 & 338 & $\Delta T / K=147.3 X_{S}[0.999]$ & $1+0.30 X_{S}$ \\
\hline $\mathrm{PEO}_{90}$ & 223 & 1.15 & $8.2 \pm 2.5$ & 2.1 & 337 & $\Delta T / K=123.7 X_{S}[0.999]$ & $1+0.37 X_{S}$ \\
\hline $\mathrm{PEO}_{80}$ & 231 & 1.27 & $9.2 \pm 2.4$ & 2.7 & 336 & $\Delta T / K=163.7 X_{S}[0.999]$ & $1+0.45 X_{S}$ \\
\hline $\mathrm{PEO}_{70}$ & 233 & 0.21 & $8.1 \pm 1.7$ & 0.4 & 335 & $\Delta T / \mathrm{K}=91.8 X_{\mathrm{S}}[0.999]$ & $1+0.19 X_{S}$ \\
\hline $\mathrm{PEO}_{60}$ & 237 & - & - & - & 335 & - & - \\
\hline $\mathrm{PEO}_{50}$ & 246 & - & - & - & 334 & - & - \\
\hline $\mathrm{PEO}_{40}$ & 258 & - & - & - & 333 & - & - \\
\hline $\mathrm{PEO}_{20}$ & 273 & - & - & - & 331 & - & - \\
\hline PMA & 286 & -0.72 & $43.4 \pm 1.1$ & -8.9 & - & - & - \\
\hline
\end{tabular}

(a) Mean value of $\Delta C_{P}$ of the polymer pair in the linear range.

\subsection{Optical Microscopy}

From $T_{\mathrm{g}}$ measurements, we note the existence of single $T_{\mathrm{g}} \mathrm{s}$ for binary PEO/PMA blends, which is also true for ternary $\mathrm{PEO} / \mathrm{PMA} / \mathrm{LiClO}_{4}$ mixtures at sufficiently small salt concentration under described experimental conditions. The heterogeneity (immiscibility) is observed only when the mass fraction of PEO is minor, $W_{\mathrm{PEO}} \leq 0.6$, and the mass fraction of salt is high, $W_{\mathrm{S}} \geq 0.05$. The optical micrographs of selected ternary $\mathrm{PEO} / \mathrm{PMA} / \mathrm{LiClO}_{4}$ systems taken at $10 \times$ magnification is shown in Table 4. The micrographs were captured at two different temperatures, i.e., $80{ }^{\circ} \mathrm{C}$ after $30 \mathrm{~min}$ (in the molten state) and $25^{\circ} \mathrm{C}$ after $24 \mathrm{~h}$ (in the solid state). As expected, the binary PEO/PMA blends in the molten state $\left(T=80^{\circ} \mathrm{C}\right)$ display only a single-phase without any visible boundary with polymer interfaces. This observation is also true for ternary mixtures with small concentration of salt (i.e., systems of $\mathrm{PEO}, \mathrm{PEO}_{80}$, and $\mathrm{PEO}_{50}$ without the presence of salt). The two-phase structure occurs when the mass fraction of $\mathrm{PEO}$ is minor, $W_{\mathrm{PEO}} \leq 0.6$, and mass fraction salt is high, $W_{\mathrm{S}} \geq 0.05$. It is supported by the micrographs of $\mathrm{PEO}_{50}$ after addition of $W_{S} \geq 0.05$, where a two-phase structure with clear boundaries at the polymer interface is observed. $\mathrm{PEO}_{50}$ with $W_{\mathrm{S}}=0.065$ displays a matrix-droplet morphology, and it starts to transform into co-continuous morphology with addition of higher salt content at $W_{S}=0.091$. This observation on $\mathrm{PEO}_{50}$ with salt may be associated to the situation (I) and (IV) as described in the introduction, where the liquid-liquid phase separation is inferred in the melt and amorphous phase of the semi-crystalline/amorphous PEO/PMA blends after addition of higher content of salt (this is in good agreement to the $T_{\mathrm{g}}$ results; system with $W_{\mathrm{PEO}} \leq 0.6$ at $W_{\mathrm{S}} \geq 0.05$, which possess two $T_{\mathrm{g}} \mathrm{s}$ that correspond to PEO and PMA). 
Table 4. Micrographs of $\mathrm{PEO} / \mathrm{PMA} / \mathrm{LiClO}_{4}$ systems at temperature of $80{ }^{\circ} \mathrm{C}$ after $30 \mathrm{~min}$ and $25^{\circ} \mathrm{C}$ after $24 \mathrm{~h}$ of isothermal annealing. Micrographs were taken with $10 \times$ magnification. The scale bar at each micrograph corresponds to $100 \mu \mathrm{m}$.

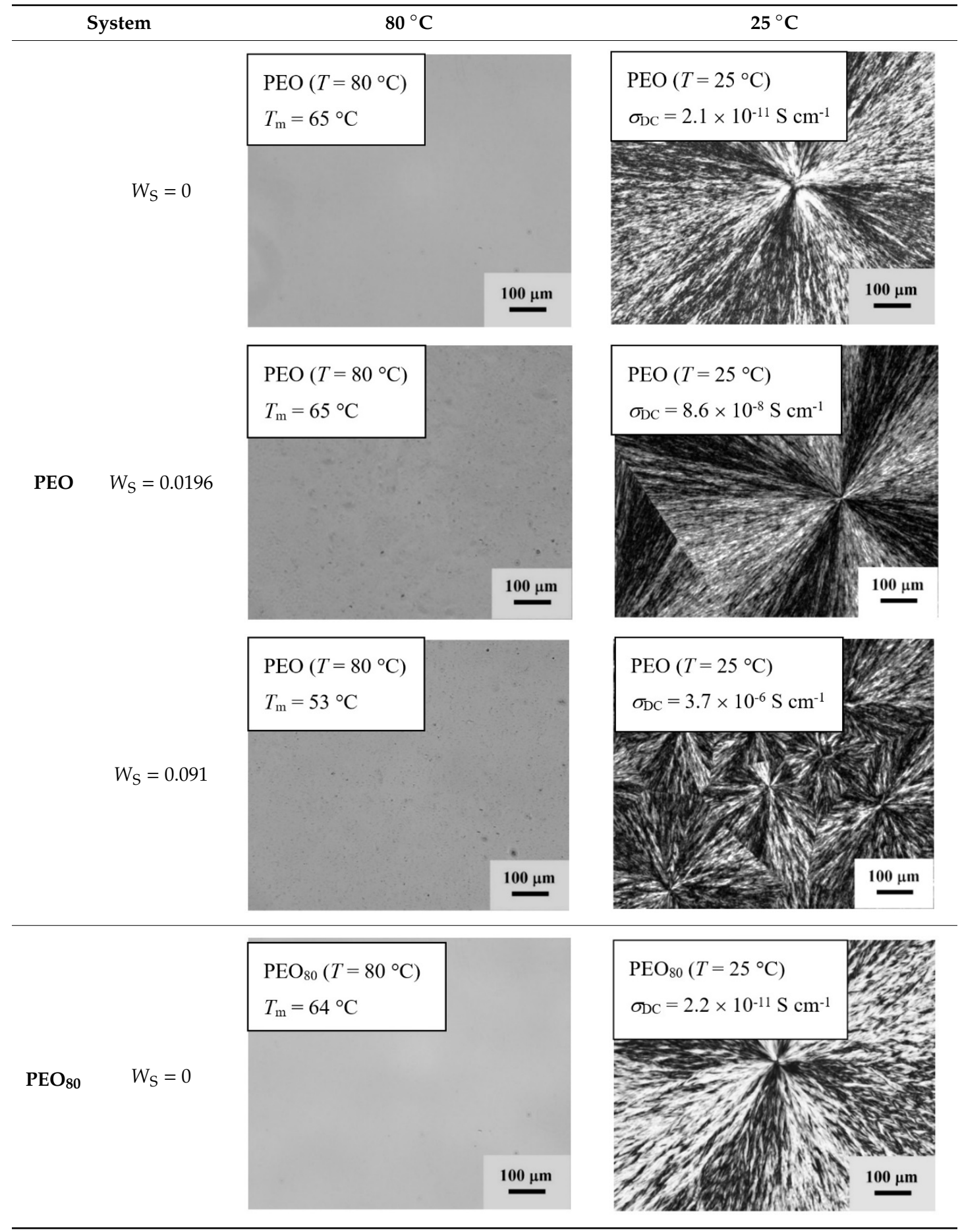


Table 4. Cont.

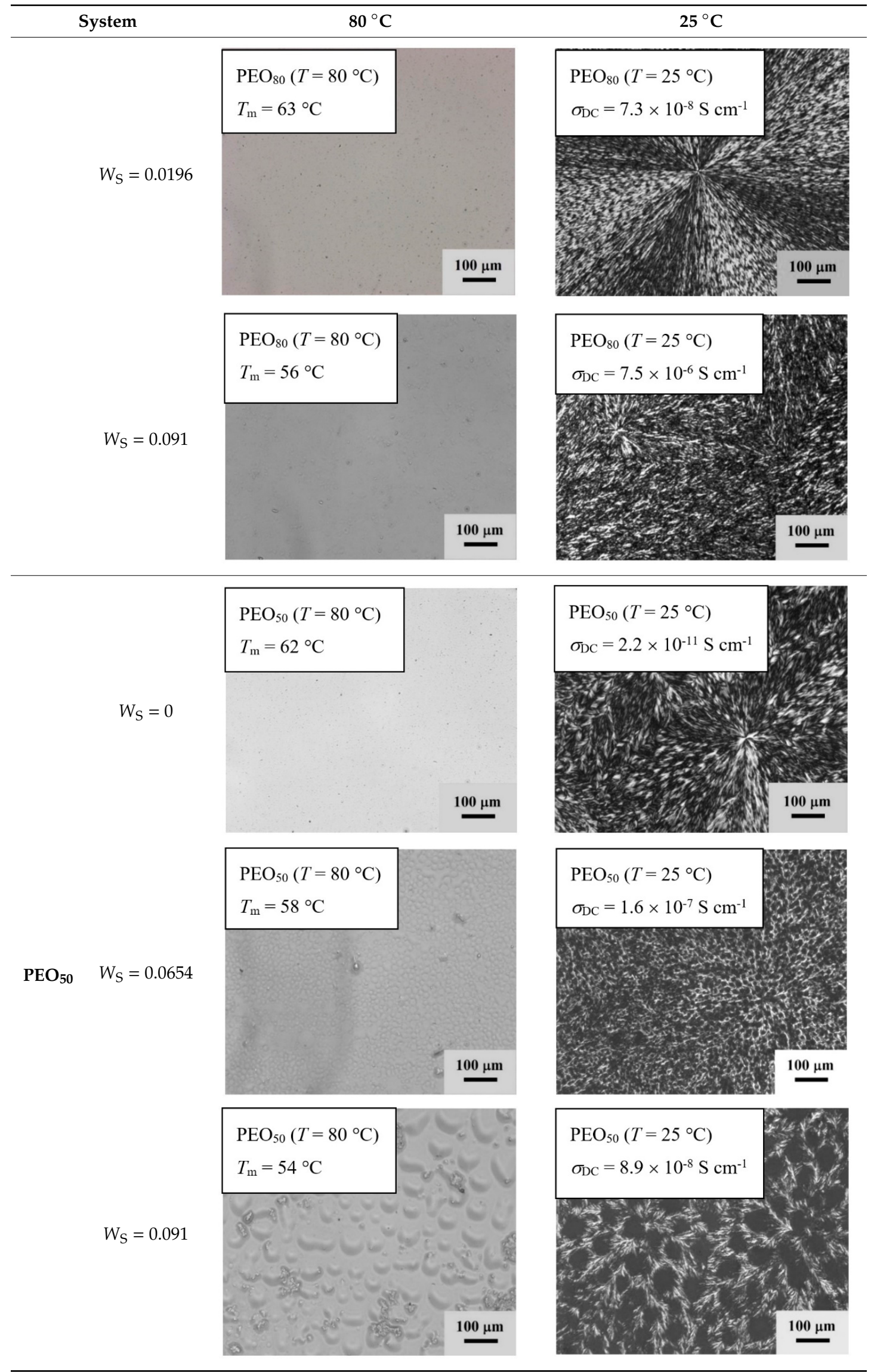


At $25^{\circ} \mathrm{C}$, where PEO is crystalline below the melting point $T_{\mathrm{m}}=\sim 65{ }^{\circ} \mathrm{C}$, the samples are placed between crossed polarizers of the optical microscope. Using polarized light, the neat PEO displays large spherulites with a fine fibrillar texture and a clear Maltese cross. As expected, the number of nucleation sites of $\mathrm{PEO}$ spherulites for $\mathrm{PEO}, \mathrm{PEO}_{80}$, and $\mathrm{PEO}_{50}$ increase with and without salt due to the exclusion of PMA and Li-salt from the PEO crystalline phase during crystallization This is also reflected by the $T_{\mathrm{m}}$ results, where the melting point depression of PEO is observed with increasing salt content. This is due the fact that PMA and Li-salt most likely have attractive interactions with PEO phases, which eventually lead to the incomplete exclusion. Coarsening and irregularity of PEO spherulite fibrils with blurred grain boundary are clearly noted for all systems at high salt content. There are several spherical dark spots of PMA within the continuous phase of PEO spherulites for $\mathrm{PEO}_{50}$ at $W_{\mathrm{S}}=0.065$ and 0.091 .

The proposed schematic diagrams of $\mathrm{PEO}_{50}$ systems at $W_{\mathrm{S}}=0$ and 0.091 in the molten and solid state based on the $T_{\mathrm{g}}$ results and polarized optical microscopy are shown in Figure 5. We conclude that both systems possess different morphologies molten at $80^{\circ} \mathrm{C}$ or isothermally crystallized at $25^{\circ} \mathrm{C}$. Immiscibility caused by liquid-liquid phase separation (at $80^{\circ} \mathrm{C}$ ) (c.f. Figure $5 \mathrm{c}$ ) and liquid-solid phase separation in $\mathrm{PEO}_{50}$ are observed while cooling down from $80^{\circ} \mathrm{C}$ to $25^{\circ} \mathrm{C}$ (c.f. Figure $5 \mathrm{~d}$ ) after addition of salt $W_{S}=0.091$. Figure 5 was assigned with the possible morphologies from Table 1 .
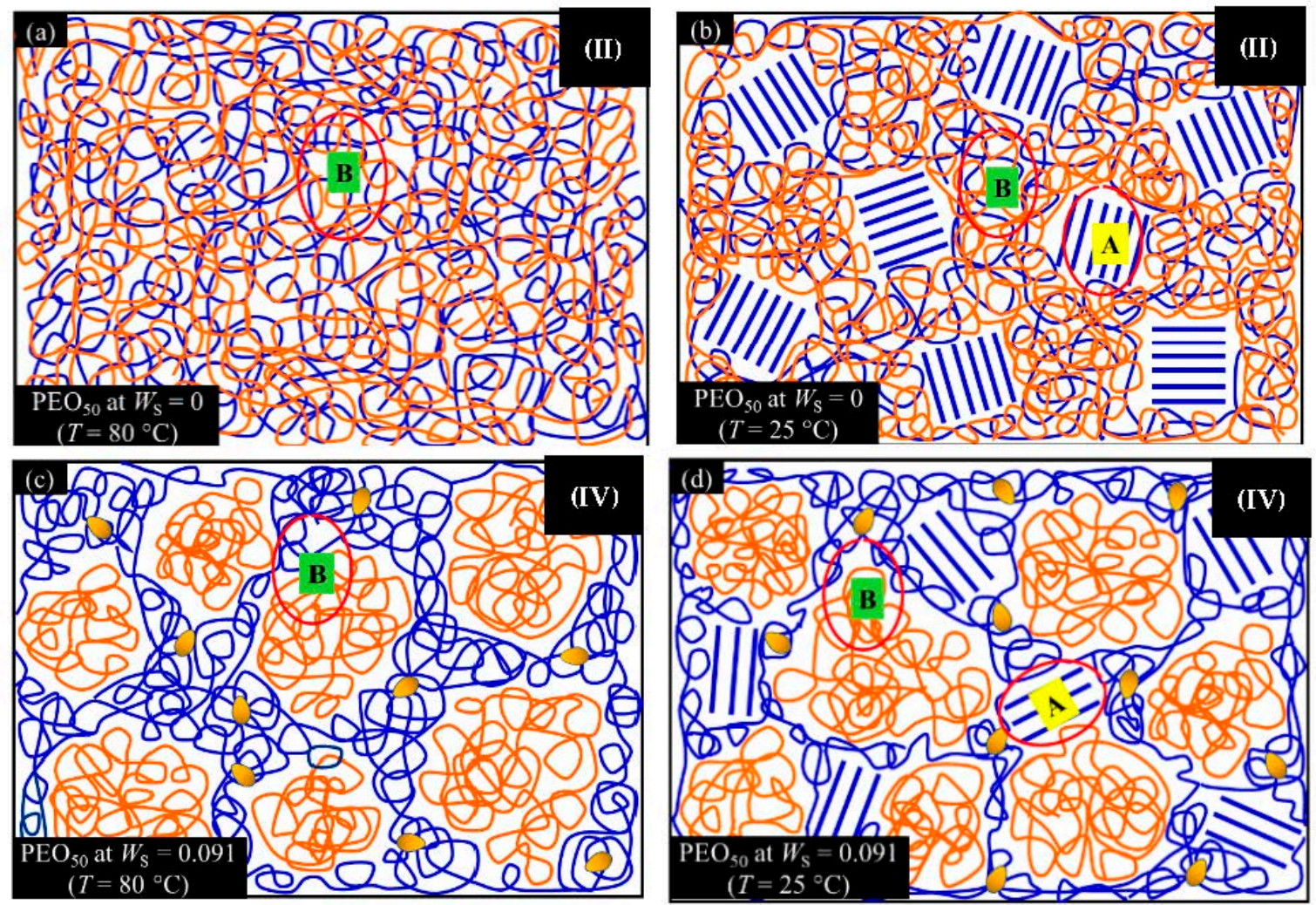

Figure 5. Schematic diagrams of $\mathrm{PEO}_{50}$ at (a) $W_{\mathrm{S}}=0$ and $\mathrm{T}=80{ }^{\circ} \mathrm{C}$; (b) $W_{\mathrm{S}}=0$ and $\mathrm{T}=25{ }^{\circ} \mathrm{C}$; (c) $W_{\mathrm{S}}=0.091$ and $\mathrm{T}=80^{\circ} \mathrm{C}$; (d) $W_{\mathrm{S}}=0.091$ and $\mathrm{T}=25^{\circ} \mathrm{C}$. Blue and orange polymer chains represent PEO and PMA, respectively. The crystalline phase of PEO is presented as the highly ordered chains (labelled as A) and the amorphous phase of PEO and PMA are presented as the entangled chains (labelled as B). The $\mathrm{LiClO}_{4}$ is presented as the yellow irregular oval-shaped entities.

\subsection{Impedance Spectroscopy}

The impedance spectra of all systems were measured at $25^{\circ} \mathrm{C}$. Selected binary systems of PEO, PMA, and its blends, such as $\mathrm{PEO}_{90}, \mathrm{PEO}_{80}, \mathrm{PEO}_{70}, \mathrm{PEO}_{60}$ and $\mathrm{PEO}_{50}$, added with different salt content will be discussed under this section, where the morphologies of these systems are correlated 
to situation (I), (II), (III), or (IV). It is widely accepted that the percolation network only bounds in the amorphous domain of salt-added systems. This phase is considered as not in thermodynamic equilibrium [28-31]. It may be adequate to discuss the dielectric relaxation process in this domain as a fluctuation-dissipation process [32]. Hence, in the following, the development of relaxation or polarization of dipoles are discussed from the phenomenological point of view.

We observe here that the real part $\left(Z^{\prime}\right)$ and imaginary part ( $\left.Z^{\prime \prime}\right)$ of impedance reflect to Ohmic resistance and non-Ohmic resistance, respectively. The quantity $Z$ " displays the characteristic frequencies mainly for dielectric (or dipole) relaxation resulting from local motions of the charged entities and electrode polarization developing from the accumulation of charged entities at the electrode-electrolyte interfaces, after being subjected to an external electric field. These characteristic frequencies are noted as $f_{\max }^{Z^{\prime \prime}}$ and $f_{\min ^{\prime}}^{Z^{\prime \prime}}$ respectively. Besides, the intersection between $Z^{\prime}$ and $Z^{\prime \prime}$ that is noted as $f_{\text {cross }}^{Z^{\prime}-Z^{\prime \prime}}$ indicates to the development of the percolation charge entities. We recognize the characteristic frequencies as the average of relaxation time constant $\left(\omega^{-1}\right)$. A system with one relaxation time $\left(\omega^{-1}\right)$ is recognized as Debye relaxation [33]. In general, these phenomena can be observed in a system with highly resistive behavior. A system with high capacitive behavior normally behaves contrarily. Apparently, the impedance plot $Z^{\prime \prime}=Z^{\prime \prime}\left(Z^{\prime}\right)$ in the $Z^{\prime}-Z^{\prime \prime}$ plane results in semicircle with a radius of $R_{\mathrm{b}} / 2$. Hence, the plot of $Z^{\prime \prime}$ vs. frequency $(f)$ as displayed in Figure 6 allows for the determination of the bulk resistance $\left(R_{\mathrm{b}}\right)$, with $\mid Z^{\prime \prime}$ max $\mid=R_{\mathrm{b}} / 2$. This $R_{\mathrm{b}}$ quantity is defined as inversely proportional to the DC conductivity $\left(R_{\mathrm{b}} \propto 1 / \sigma_{\mathrm{DC}}\right)$. Hence, investigation of the relaxation process in terms of impedance from phenomenological perspective may implicitly elucidate the dielectric and electrical behavior of the system.

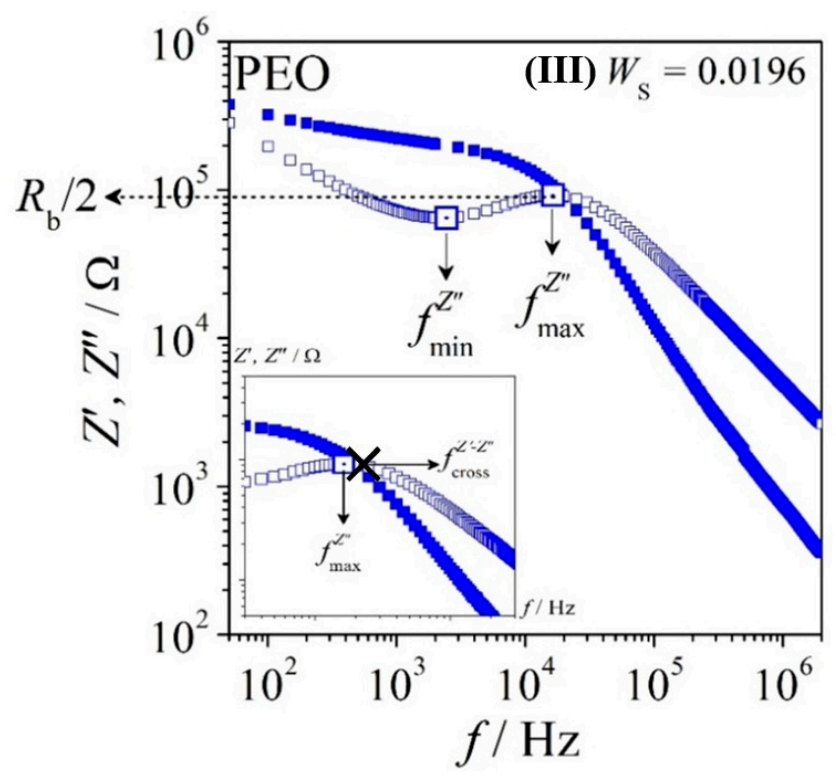

Figure 6. Frequency-dependent impedance spectra of PEO with mass fraction of salt 0.0196 $\left(\sim 2\right.$ wt.\%); Solid and open markers represent the real part $\left(Z^{\prime}\right)$ and the imaginary part $\left(Z^{\prime \prime}\right)$ of impedance, respectively.

Figure 6 represents the impedance spectra, $Z^{\prime}(f)$ and $Z^{\prime \prime}(f)$, of PEO at low salt content $W_{S}=0.0196$. We observe the existence of the three characteristic frequencies as mentioned before in the impedance spectra of the system. The $f_{\max }^{Z^{\prime \prime}}$ is noted as the main dipole relaxation, which originates from the alignment of dipoles resulting from the interplay of the sample's resistance and capacitance in the fully stabilized network. The $f_{\min }^{Z \prime \prime}$ is noted as the electrode polarization (or called a double-layer capacitance due to the accumulation of charges at the interface of electrode and electrolyte) especially at low frequency. This observation frequently leads to dispersion of relaxation times (i.e., $f_{\max }^{Z^{\prime \prime}}<f_{\text {cross }}^{Z^{\prime}-Z^{\prime \prime}}$ ) and normally becomes severe in the system with high salt content because of the inhomogeneity in 
the system (c.f. red triangle markers for PEO-salt in Figure 7). However, the distance of $f_{\max }^{Z^{\prime \prime}}$ and $f_{\text {cross }}^{Z^{\prime}-Z^{\prime \prime}}$ for PEO at $W_{S}=0.0196$ is small which may indicate that the system is close to Debye relaxation. We suggest that the orientation of dipolar entities in PEO-salt is dominantly restricted to short-range motion (local motion) and insignificant long-range motion. The PMA-salt has no $f_{\max }^{Z^{\prime \prime}}$ at low salt content and one broad $f_{\max }^{Z^{\prime \prime}}$ is observed in $Z^{\prime \prime}$ spectrum of system with high salt content at frequency. This indicates no dipolar entities in PMA with low salt content and only appears after adding higher content of salt under the experimental condition.

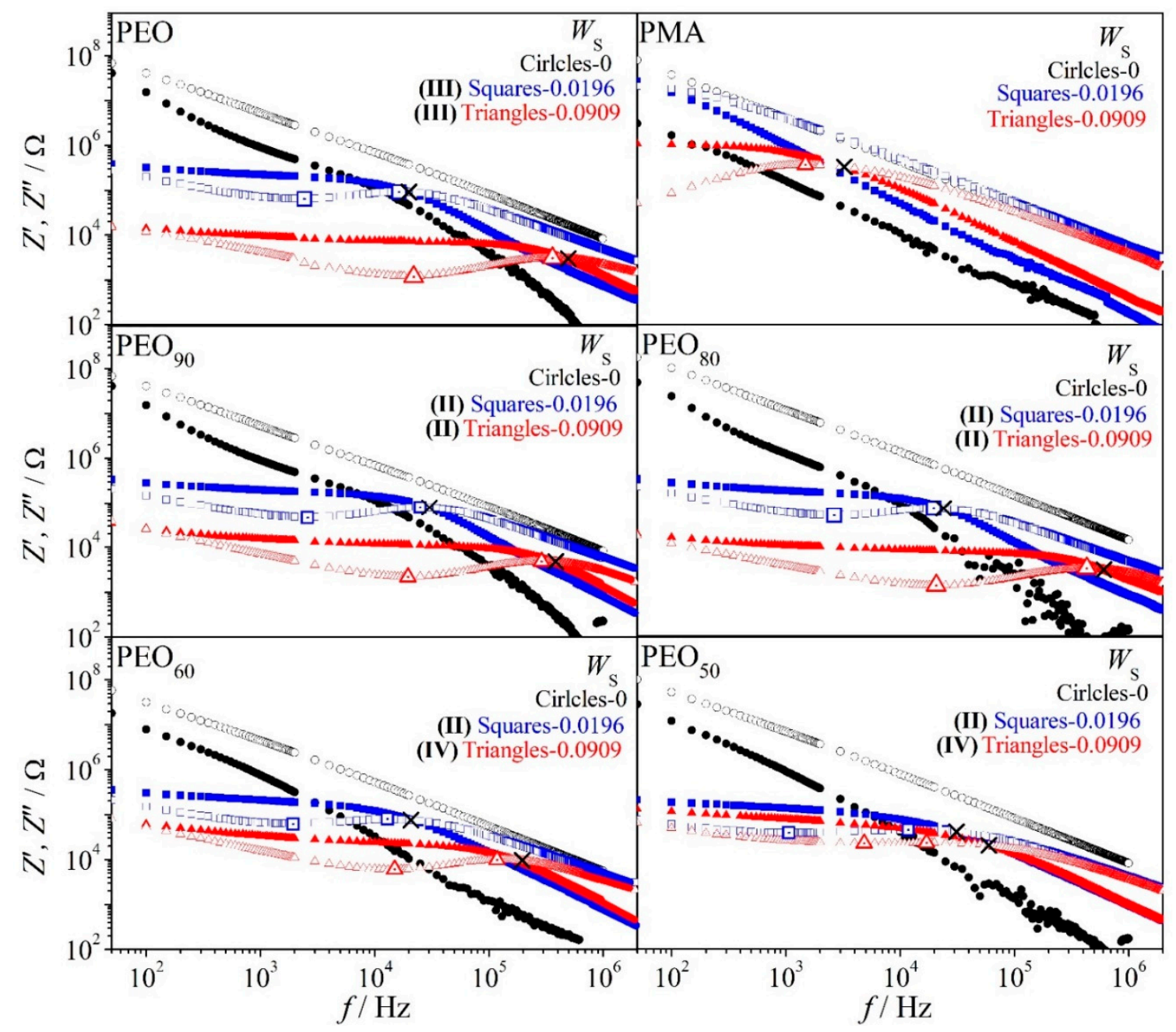

Figure 7. Frequency-dependent impedance spectra of $\mathrm{PEO} / \mathrm{PMA} / \mathrm{LiClO}_{4}$ systems at different $W_{\mathrm{S}}$ at $25{ }^{\circ} \mathrm{C}$; solid and open markers represent the real part $\left(Z^{\prime}\right)$ and the imaginary part $\left(Z^{\prime \prime}\right)$ of impedance, respectively.

Figure 7 displays the impedance spectra of PEO/PMA mixtures at different $W_{\mathrm{S}}$. PEO, PMA, and its blends with salt are above the glassy state of parent polymers (c.f. glass transition temperature). $R_{\mathrm{b}}$ values clearly decrease with increasing salt content for all systems and this indirectly infers the increasing DC conductivity. For system with PEO in excess, under $W_{\mathrm{S}}=$ const., either for low or high content of salt, the $R_{\mathrm{b}}$ decreases slightly as compared to the binary PEO/Li salt system. This may indicate that the system with PEO in excess behaves similar to PEO especially at low salt content, for instance, $\mathrm{PEO}_{80}$ at $W_{\mathrm{S}}=0.0196$ (low content of salt). A large distribution of relaxation times is observed for PEO and $\mathrm{PEO}_{80}$ with high salt content $W_{\mathrm{S}}=0.0909$ as well as for $\mathrm{PEO}_{50}$ at $W_{\mathrm{S}}=0.0196-0.0909$ and PMA at $W_{S}=0.0909$, based on the observation of the characteristic frequencies $f_{\max }^{Z^{\prime \prime}}<f_{\text {cross }}^{Z^{\prime}-Z^{\prime \prime}}$ at the respective compositions. Additionally, the presence of $f_{\min ^{\prime \prime}}^{Z^{\prime \prime}}$ which points towards electrode polarization, may also 
contributes to the distribution of relaxation times of a system (i.e., $\mathrm{PEO}-\mathrm{PEO}_{50}$ at $W_{\mathrm{S}} \geq 0.0196$ in Figure 7). This deviation may indicate to non-Debye response that normally occurs because of the increase in inhomogeneity in the system. We may summarize that, at high salt content, the distribution of characteristic frequencies is always denoted as

$$
f_{\max }^{Z^{\prime \prime}}<f_{\text {cross }}^{Z^{\prime}-Z^{\prime \prime}}
$$

whereas at low salt content, it is seen as

$$
f_{\max }^{Z^{\prime \prime}} \approx f_{\text {cross }}^{Z^{\prime}-Z^{\prime \prime}}
$$

At $W_{\mathrm{S}}=$ const. especially at high salt content, when PMA is in excess or in symmetric systems (i.e., $\left.W_{\mathrm{PEO}} \leq 0.5\right) R_{\mathrm{b}}$ and characteristic frequencies shift to higher and lower values, respectively, as compared to binary $\mathrm{PEO} / \mathrm{Li}$ salt blends or system with PEO in excess. It is noted that these systems are seen as liquid-liquid phase separated as reflected in the $T_{\mathrm{g}}$ results of the same system, where situations (I) and (IV) are correlated. This behavior may indicate preferential localization of salt in the different polymer phases of the immiscible ternary mixture. For instance, based on the $T_{\mathrm{g}}$ results, we may assume that the PEO phase in $\mathrm{PEO}_{50}$ at $W_{\mathrm{S}}=0.091$ contains less salt as compared to the binary $\mathrm{PEO} / \mathrm{Li}$ salt system at the same composition. This phenomenon might be one of the reasons for the enhancement of the bulk resistance as well as large deviation from Debye response in the liquid-liquid phase separated systems.

Further insight, Figure 7 illustrates that impedance spectra of PEO/PMA blends comprise low and high concentration of salt, respectively. Interesting points of the impedance spectra are suggested as follows. Blends with PEO in excess show similar behavior of neat PEO at low salt concentration. The amorphous network-like phase of PEO in the blends is almost not influenced by the PMA phase. The PEO amorphous phase contains slightly more salt than in the neat PEO; as a consequence, bulk resistance is slightly reduced. Additionally, we note that $f_{\min ^{\prime}}^{Z^{\prime \prime}} f_{\max }^{Z^{\prime \prime}}(\mathrm{PEO})<f_{\min ^{\prime}}^{Z^{\prime \prime}} f_{\max }^{Z^{\prime \prime}}\left(\mathrm{PEO}_{80}\right)$ and $f_{\text {cross }}^{Z^{\prime}-Z^{\prime \prime}}(\mathrm{PEO})<f_{\text {cross }}^{Z^{\prime}-Z^{\prime \prime}}\left(\mathrm{PEO}_{80}\right)$. Enhanced content of PMA in blends leads increasingly to higher $R_{\mathrm{b}}$ at $Y_{\mathrm{S}}=$ const. On top of that, $f_{\text {min }^{\prime}}^{Z^{\prime \prime}} f_{\text {max }}^{Z^{\prime \prime}}$, and $f_{\text {cross }}^{Z^{\prime}-Z^{\prime \prime}}$ shift to lower values. It indicates "effective" salt content of the amorphous PEO phase lessens more and more. Again, one observes more dispersion of relaxation times, $f_{\min }^{Z^{\prime \prime}}<f_{\max }^{Z^{\prime \prime}}<f_{\text {cross }}^{Z^{\prime}-Z^{\prime \prime}}$. In short, dielectric behavior of PEO and of the blends with PMA is governed by amorphous network-like phases. Addition of Li-salt leads to dissolution of low "effective" amounts of salt in these phases. Therefore, corresponding polymer-salt mixture can be seen to good approximation as a perfect solution. This PEO-like behavior is maintained when low content PMA is added to PEO at room temperature.

Figure 8 depicts the double-logarithmic plots of conductivity $\left(\sigma_{\mathrm{DC}}\right)$ as a function of salt concentration $\left(Y_{S}\right)$. The salt concentration $Y_{S}$ is defined as the ratio of mass of salt to the mass of polymer. The double-logarithmic plots of $\sigma_{\mathrm{DC}}$ vs. $Y_{\mathrm{S}}$ for $\mathrm{PEO} / \mathrm{PMA} / \mathrm{LiClO}_{4}$ systems denote a power law dependence resulting from the functional relationship between the two quantities [27,34]. The linear relationship of the double-logarithmic plot of $\sigma_{\mathrm{DC}}$ vs. $Y_{\mathrm{S}}$ can be read as

$$
\sigma_{\mathrm{DC}}=\sigma_{o} Y_{\mathrm{S}}^{x}
$$

which yields the quantity of $\sigma_{\mathrm{o}}$ and allows for the estimation of the exponent $x$ [27,34]. The exponent $x$ in Equation (11) is the extent of association between salt molecules and the polymer segments. The quantity $\sigma_{\mathrm{o}}$ in Equation (11) is the simplified form of charge mobility in the system. The full form equation can be read as

$$
\sigma_{\mathrm{DC}}=N_{\mathrm{A}} e \mu \alpha \frac{\rho_{\mathrm{P}}}{M_{\mathrm{S}}} \gamma_{\mathrm{S}}^{x}
$$

where $\mu \alpha$ is the mobility, $N_{\mathrm{A}}$ is the Avogadro's constant, $e$ is the elementary charge, $\rho_{\mathrm{p}}$ is the polymer's density, and $M_{S}$ represents the molar mass of $\mathrm{LiClO}_{4}$, where the molecular characteristics 
for determination of quantity $\mu \alpha$ are listed in Table 1 . The density of each blend was calculated using the additivity rule. All characteristic quantities of the linear regression function for all systems adopted from Equation (12) are summarized in Table 5.

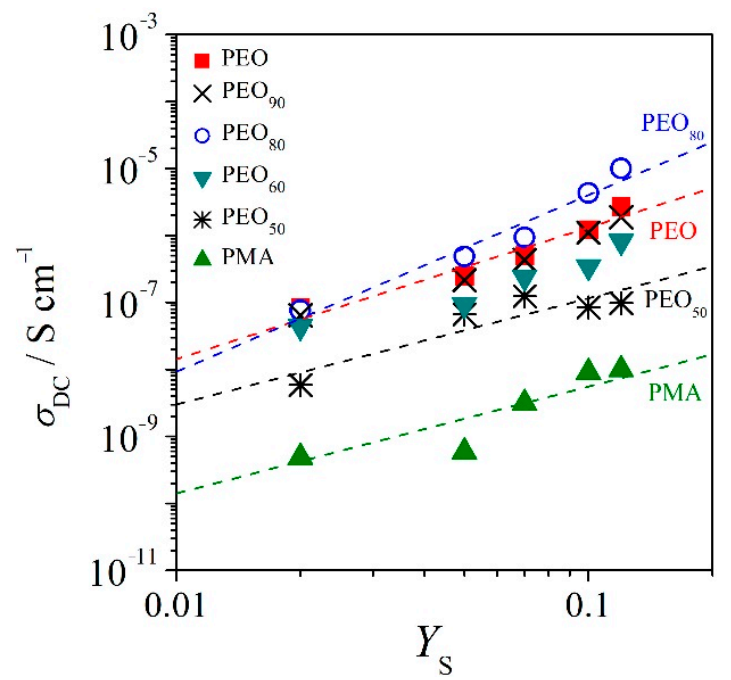

Figure 8. Conductivity $\left(\sigma_{\mathrm{DC}}\right)$ of $\mathrm{PEO} / \mathrm{PMA} / \mathrm{LiClO}_{4}$ systems versus salt concentration at temperature $25^{\circ} \mathrm{C}$; the dashed curves are the linear regressions after Equation (11).

Table 5. The characteristic quantities obtained from Equation (12) for PEO/PMA/LiClO 4 systems.

\begin{tabular}{|c|c|c|c|c|}
\hline Systems & Regression Function/S $\mathrm{cm}^{-1}$ & Correlation & $X$ & $\frac{\mu \alpha}{\mu \mathrm{cm}^{2}} \stackrel{\mathrm{V}^{-1}}{\mathrm{~s}^{-1}}$ \\
\hline PEO & $\sigma_{\mathrm{DC}}=2.82 \times 10^{-4} Y_{\mathrm{S}}^{1.96}$ & 0.950 & 1.96 & $2.57 \times 10^{-7}$ \\
\hline $\mathrm{PEO}_{90}$ & $\sigma_{\mathrm{DC}}=1.10 \times 10^{-4} Y_{\mathrm{S}}^{1.87}$ & 0.978 & 1.87 & $1.01 \times 10^{-7}$ \\
\hline $\mathrm{PEO}_{80}$ & $\sigma_{\mathrm{DC}}=4.19 \times 10^{-3} Y_{\mathrm{S}}^{2.28}$ & 0.944 & 2.28 & $3.81 \times 10^{-6}$ \\
\hline $\mathrm{PEO}_{70}$ & $\sigma_{\mathrm{DC}}=3.16 \times 10^{-5} Y_{\mathrm{S}}^{1.68}$ & 0.901 & 1.68 & $2.87 \times 10^{-8}$ \\
\hline $\mathrm{PEO}_{60}$ & $\sigma_{\mathrm{DC}}=2.79 \times 10^{-6} Y_{\mathrm{S}}^{1.58}$ & 0.944 & 1.58 & $2.54 \times 10^{-9}$ \\
\hline $\mathrm{PEO}_{50}$ & $\sigma_{\mathrm{DC}}=1.95 \times 10^{-6} Y_{\mathrm{S}}^{1.59}$ & 0.957 & 1.59 & $1.77 \times 10^{-10}$ \\
\hline PMA & $\sigma_{\mathrm{DC}}=1.57 \times 10^{-6} Y_{\mathrm{S}}^{1.59}$ & 0.906 & 1.59 & $1.43 \times 10^{-9}$ \\
\hline
\end{tabular}

From Figure 8, binary PMA/Li salt systems display the lowest $\sigma_{\mathrm{DC}}$ as compared to the binary $\mathrm{PEO} / \mathrm{Li}$ salt blends and in the blends of PEO/PMA systems due to the fact that the $\mu \alpha$ mobility in PMA is by three orders of magnitude lower than in PEO. Moreover, PEO has stronger association between salt molecules and polymer segments than salt in PMA, as reflected in exponent $x=1.96$ for PEO as compared to $x=1.59$ for PMA, which might be the reason for lower $\sigma_{\mathrm{DC}}$ of PMA. This indicates that the salts interact with PMA very weakly, which is in agreement with the $T_{\mathrm{g}}$ findings of the systems. $\mathrm{PEO}_{80}$ at $W_{\mathrm{S}}=0.107$ has the highest value of ion conductivity at $1.43 \times 10^{-5} \mathrm{~S} \mathrm{~cm}^{-1}$ as compared to the other blend compositions with $W_{\mathrm{S}}=$ const. This is in good agreement where $\mathrm{PEO}_{80}$ also has the highest value of exponent $x=2.28$ and $\mu \alpha=3.81 \times 10^{-6} \mathrm{~cm}^{2} \mathrm{~V}^{-1} \mathrm{~s}^{-1}$ as compared to the other blend compositions. The blends $W_{\mathrm{PEO}}=0.5$ exhibit lower values of $\mu \alpha$ mobility than PEO but higher than $\mu \alpha$ mobility of PMA. Hence, we may conclude the ionic conductivities of PEO/PMA/Li blends are dominated by the percolation of $\mathrm{PEO}$ in the amorphous phase. Blending small contents of PMA with PEO, when PEO in excess with addition of salt enhances the $\sigma_{\mathrm{DC}}$ of systems as compared to binary systems of PEO and salt with $W_{\mathrm{S}}=$ const. However, the conductivities of the symmetric system, i.e., $\mathrm{PEO}_{50}$, decrease by two orders of magnitude as compared to PEO-salt systems. This might be caused by the fact that the Li cation is not coordinating well with the chains of both polymers for the phase-separated systems at room temperature. Therefore, we may assume that when PEO with addition of salt is dispersed 
in PMA domains such as for systems $W_{\mathrm{PEO}} \leq 0.5$ where the Li-salt in the PEO phase may not have sufficient percolating paths unlike the systems with PEO in excess.

\section{Conclusions}

The influence of salt in binary PEO/PMA blends was elucidated using DSC, OM, and EIS. The changes in phase behavior indicated by $T_{\mathrm{g}}$ and morphologies are correlated to the dielectric relaxation using impedance spectroscopy. Based on $T_{\mathrm{g}}$, PEO/PMA remains miscible when PEO is in excess after the addition of low contents of salt. However, this behavior is not seen in systems of $W_{\mathrm{PEO}}<0.6$ at salt content $W_{\mathrm{S}}>0.05$ due to the fact of preferential solubility of salt in the PEO phase, which leads to liquid-liquid phase separation. These findings are well reflected with the results from optical microscopy, where the morphologies of PEO/PMA blends with or without addition of salt can be distinguished in agreement with $T_{\mathrm{g}}$ findings. Subsequently, the evaluation of polarization and dielectric relaxation of dipoles in the composition dependent PEO/PMA blends with salts at room temperature are discussed from the phenomenological point of view. Dielectric relaxation for systems with PEO in excess behaves similar as in PEO after the addition of salt. Main dipole relaxation and bulk resistance of the salt-added systems are shifted to higher frequency and lower impedance, respectively, with increasing salt content. This phenomenon is also true for all systems under discussion. Moreover, the double-logarithmic plot of $\sigma_{\mathrm{DC}}$ vs. salt concentration manifests the presence of power-law distribution between the quantities. It indicates that the conductivity of the compositional-dependent PEO/PMA blends with salts are governed by the conductivity of PEO, as the power-law distribution of compositions with PEO in excess are higher than in PMA.

Author Contributions: Conceptualization, S.I.A.H.; investigation, S.I.A.H.; methodology, S.I.A.H.; supervision, C.H.C. and J.K.; writing - original draft, S.I.A.H.; writing—review and editing, C.H.C. and J.K. All authors have read and agreed to the published version of the manuscript.

Funding: This research was funded by Ministry of Education, Malaysia, grant number 600-RMI/FRGS 5/3 (67/2013).

Acknowledgments: The authors would also like to express our gratitude towards Ministry of Education, Malaysia for the "Fundamental Research Grant Scheme" grant (FRGS) (600-RMI/FRGS 5/3 (67/2013)) and MyBrain15 (MyPhD) for financially supporting this study.

Conflicts of Interest: The authors declare no conflict of interest.

\section{Appendix A}

Table A1. Salt concentration of the systems.

\begin{tabular}{ccc}
\hline$W_{\mathrm{S}}=\frac{m_{\mathrm{S}}}{m_{\mathrm{S}}+m_{\mathrm{PEO}}+m_{\mathrm{PMA}}}$ & $X_{\mathrm{S}}=\frac{n_{\mathrm{S}}}{n_{\mathrm{S}}+n_{\mathrm{PEO}}+n_{\mathrm{PMA}}}(\mathbf{a})$ & $Y_{\mathrm{S}}=\frac{m_{\mathrm{S}}}{m_{\mathrm{PEO}}+m_{\mathrm{PMA}}}$ \\
0 & 0 & 0 \\
0.0196 & 0.0082 & 0.02 \\
0.0476 & 0.0203 & 0.05 \\
0.0654 & 0.0282 & 0.07 \\
0.0909 & 0.0398 & 0.10 \\
0.107 & 0.0473 & 0.12 \\
0.130 & 0.0585 & 0.15 \\
\hline
\end{tabular}

\section{References}

1. Tarascon, J.M.; Armand, M. Issues and challenges facing rechargeable lithium batteries. Nature 2001, 414, 359-367. [CrossRef] [PubMed]

2. Berthier, C.; Gorecki, W.; Minier, M.; Armand, M.B.; Chabagno, J.M.; Rigaud, P. Microscopic investigation of ionic conductivity in alkali metal salts-poly(ethylene oxide) adducts. Solid State Ion. 1983, 11, 91-95. [CrossRef] 
3. Lascaud, S.; Perrier, M.; Armand, M.; Prud'homme, J.; Kapfer, B.; Vallée, A.; Gauthier, M. Evidence for ion pairs and/or triple ions from transport measurements in mixed-alkali polyether electrolytes. Electrochim. Acta 1998, 43, 1407-1414. [CrossRef]

4. Gray, F.; Armand, M. Polymer Electrolytes. Handb. Battery Mater. 2011, 989. [CrossRef]

5. Weston, J.E.; Steele, B.C.H. Effects of inert fillers on the mechanical and electrochemical properties of lithium salt-poly(ethylene oxide) polymer electrolytes. Solid State Ion. 1982, 7, 75-79. [CrossRef]

6. Dygas, J.R.; Misztal-Faraj, B.; Florjańczyk, Z.; Krok, F.; Marzantowicz, M.; Zygadło-Monikowska, E. Effects of inhomogeneity on ionic conductivity and relaxations in PEO and PEO-salt complexes. Solid State Ion. 2003, 157, 249-256. [CrossRef]

7. Marzantowicz, M.; Dygas, J.R.; Krok, F.; Łasińska, A.; Florjańczyk, Z.; Zygadło-Monikowska, E.; Affek, A. Crystallization and melting of PEO:LiTFSI polymer electrolytes investigated simultaneously by impedance spectroscopy and polarizing microscopy. Electrochim. Acta 2005, 50, 3969-3977. [CrossRef]

8. Pedemonte, E.; Polleri, V.; Turturro, A.; Cimmino, S.; Silvestre, C.; Martuscelli, E. Thermodynamics of poly(ethylene oxide)-poly(methyl methacrylate) blends: Prediction of miscibility based on the corresponding-states theory. Polymer 1994, 35, 3278-3281. [CrossRef]

9. Pfefferkorn, D.; Sonntag, S.; Kyeremateng, S.O.; Funke, Z.; Kammer, H.W.; Kressler, J. Pressure-volume-temperature data and surface tension of blends of poly(ethylene oxide) and poly(methyl acrylate) in the melt. J. Polym. Sci. Part B Polym. Phys. 2010. [CrossRef]

10. Jeddi, K.; Qazvini, N.T.; Jafari, S.H.; Khonakdar, H.A. Enhanced ionic conductivity in PEO/PMMA glassy miscible blends: Role of nano-confinement of minority component chains. J. Polym. Sci. Part B Polym. Phys. 2010, 48, 2065-2071. [CrossRef]

11. Rocco, A.M.; Fonseca, C.P.; Loureiro, F.A.M.; Pereira, R.P. A polymeric solid electrolyte based on a poly(ethylene oxide)/poly(bisphenol A-co-epichlorohydrin) blend with LiClO4. Solid State Ion. 2004, 166, 115-126. [CrossRef]

12. Rocco, A.M.; de Assis Carias, A.; Pereira, R.P. Polymer electrolytes based on a ternary miscible blend of poly(ethylene oxide), poly(bisphenol A-co-epichlorohydrin) and poly(vinyl ethyl ether). Polymer 2010, 51, 5151-5164. [CrossRef]

13. Halim, S.I.A.; Chan, C.H.; Winie, T. Thermal, conductivity and molecular interaction studies of poly(ethylene oxide)/poly(methyl acrylate) solid polymer electrolytes. Macromol. Symp. 2017, 371, 114-124. [CrossRef]

14. Radhakrishnan, S.; Venkatachalapathy, P.D. Effect of casting solvent on the crystallization in PEO/PMMA blends. Polymer 1996, 37, 3749-3752. [CrossRef]

15. Hashifudin, A.; Sim, L.H.; Chan, C.H.; Ramli, H. Phase behaviour and morphology of composite comprising of poly(ethylene oxide), polyacrylate and lithium perchlorate. Compos. Interfaces 2014, 21, 797-805. [CrossRef]

16. Tong, Y.; Lin, Y.; Wang, S.; Song, M. A study of crystallisation of poly (ethylene oxide) and polypropylene on graphene surface. Polymer 2015, 73, 52-61. [CrossRef]

17. Mamun, A.; Bazuin, C.G.; Prud'Homme, R.E. Morphologies of various polycaprolactone/polymer blends in ultrathin films. Macromolecules 2015, 48, 1412-1417. [CrossRef]

18. Woo, E.M.; Chou, Y.H.; Chiang, W.J.; Chen, I.T.; Huang, I.H.; Kuo, N.T. Amorphous phase behavior and crystalline morphology in blends of poly(vinyl methyl ether) with isomeric polyesters: Poly(hexamethylene adipate) and poly(e-caprolactone). Polym. J. 2010, 42, 391-400. [CrossRef]

19. Cheng, S.; Smith, D.M.; Pan, Q.; Wang, S.; Li, C.Y. Anisotropic ion transport in nanostructured solid polymer electrolytes. RSC Adv. 2015, 5, 48793-48810. [CrossRef]

20. Halim, S.I.A.; Chan, C.H.; Sim, L.H. Thermal properties and intermolecular interaction of blends of poly(ethylene oxide) and poly(methyl acrylate). Macromol. Symp. 2016, 365, 95-103. [CrossRef]

21. Abdul Halim, S.I.; Chan, C.H.; Kammer, H.-W. About glass transition in polymer-salt mixtures. Polym. Test. 2019, 79, 105994. [CrossRef]

22. O'Neil, M.J. The Merck Index - An Encyclopedia of Chemicals, Drugs, and Biologicals; RSC Publishing: Cambridge, UK, 2013; ISBN 9780874216561.

23. Lascaud, S.; Perrier, M.; Vallee, A.; Besner, S.; Prudhomme, J.; Armand, M. Phase-Diagrams and conductivity behavior of poly(ethylene oxide) molten-salt rubbery electrolytes. Macromolecules 1994, 27, 7469-7477. [CrossRef]

24. Angell, C.A.; Liu, C.; Sanchez, E. Rubbery solid electrolytes with dominant cationic transport and high ambient conductivity. Nature 1993, 362, 137-139. [CrossRef] 
25. Chan, C.H.; Kammer, H.-W.; Sim, L.H.; Nasir, N.H.A.; Winie, T. On the thermodynamics of solid solutions of polymer and salt. Polym. Eng. Sci. 2012, 52, 2277-2284. [CrossRef]

26. Abdul Nasir, N.H.; Chan, C.H.; Kammer, H.W.; Sim, L.H.; Azahan Yahya, M.Z. Ionic conductivity in solutions of poly(ethylene oxide) and lithium perchlorate. Macromol. Symp. 2010, 290, 46-55. [CrossRef]

27. Harun, F.; Chan, C.H.; Winie, T. Influence of molar mass on the thermal properties, conductivity and intermolecular interaction of poly(ethylene oxide) solid polymer electrolytes. Polym. Int. 2017, 66, 830-838. [CrossRef]

28. Sanditov, D.S.; Ojovan, M.I. On relaxation nature of glass transition in amorphous materials. Phys. B Condens. Matter 2017, 523, 96-113. [CrossRef]

29. Angell, C.A.; Sivarajan, S. Glass Transition. In Reference Module in Materials Science and Materials Engineering; Elsevier: Amsterdam, The Netherlands, 2017; Volume 4, pp. 124-133. ISBN 9780128035818.

30. Jacob, K.T.; Prabhudev, S.; Mallya, R.M. Resolution of conflicting views on thermodynamics of glass transition: A unified model. Bull. Mater. Sci. 2010, 33, 603-609. [CrossRef]

31. Stillinger, F.H.; Debenedetti, P.G. Glass transition thermodynamics and kinetics. Annu. Rev. Condens. Matter Phys. 2013, 4, 263-285. [CrossRef]

32. Chan, C.H.; Kammer, H.W. Low frequency dielectric relaxation and conductance of solid polymer electrolytes with PEO and blends of PEO and PMMA. Polymers 2020, 12, 1009. [CrossRef]

33. Hill, R.M.; Dissado, L.A. Debye and non-debye relaxation. J. Phys. C Solid State Phys. 1985, 18, $3829-3836$. [CrossRef]

34. Chan, C.H.; Kammer, H.-W. Properties of solid solutions of poly(ethylene oxide)/epoxidized natural rubber blends and $\mathrm{LiClO}_{4}$. J. Appl. Polym. Sci. 2008, 110, 424-432. [CrossRef]

Publisher's Note: MDPI stays neutral with regard to jurisdictional claims in published maps and institutional affiliations. 